\title{
əIndividual and Combined Impacts of Tropical Indo-Pacific SST Anomalies on Interannual Variation of the Indochina Peninsular Precipitation
}

\author{
YIYA YANG \\ Center for Monsoon System Research, Institute of Atmospheric Physics, Chinese Academy of Sciences, and College of \\ Earth and Planetary Sciences, University of Chinese Academy of Sciences, Beijing, China \\ RENGUANG WU \\ School of Earth Sciences, Zhejiang University, Hangzhou, and Center for Monsoon System Research, Institute of \\ Atmospheric Physics, Chinese Academy of Sciences, Beijing, China \\ CHENGHAi WANG \\ College of Atmospheric Sciences, Lanzhou University, Lanzhou, China
}

(Manuscript received 3 April 2019, in final form 24 September 2019)

\begin{abstract}
This study documents interannual rainfall variations over the Indochina Peninsula (ICP) during the rainy season and individual and combined influences of tropical Indo-Pacific sea surface temperature (SST) anomalies. The rainfall variability is large along the west coast in May-June, along the west coast and over the eastern mountains in July-August, and along the central Vietnam coast in September-November. More rainfall in MayJune, July-August, and October-November occurs in the La Niña decaying years, La Niña decaying years and/ or El Niño developing years, and La Niña developing years, respectively. The May-June rainfall variation along the west coast is associated with equatorial central-eastern Pacific (EP), south Indian Ocean, and western North Pacific SST anomalies. The July-August rainfall variation along the west coast and over the eastern mountains is related to equatorial central Pacific and tropical southeastern Indian Ocean SST anomalies. The OctoberNovember rainfall variation along the central Vietnam coast is affected by EP and tropical western Indian Ocean SST anomalies. The EP and tropical western Indian Ocean SST influence is through anomalous Walker circulation. The south Indian Ocean SST influence is via cross-equatorial flows. The tropical southeastern Indian Ocean SST influence is via an anomalous cross-equatorial overturning circulation. The equatorial central Pacific and western North Pacific SST influence is via a Rossby wave-type response. The analysis illustrates the importance of combined effects of regional SST anomalies on the ICP precipitation variation in different stages of the rainy season. Numerical experiments with SST anomalies imposed in different regions confirm the combined effects of the Indo-Pacific SST anomalies on the ICP rainfall variation.
\end{abstract}

\section{Introduction}

The Indochina Peninsula (ICP) lies between the Pacific and Indian Oceans. It is a transition zone between the Indian monsoon and the East Asia-western North Pacific (WNP) monsoon (Wang and LinHo 2002). Climatologically, large precipitation is observed along the west coast and over the eastern mountainous region in

๑ Denotes content that is immediately available upon publication as open access.

Corresponding author: Renguang Wu, renguang@zju.edu.cn summer and along the east coast of central Vietnam in fall (Yang and $\mathrm{Wu}$ 2019). The topographic effect of eastern mountains on rainfall is illustrated by $\mathrm{Xu}$ et al. (2007). The climate variability over the ICP is associated with the Indian monsoon and the East Asia-WNP monsoon (Tao and Chen 1987; Lau and Yang 1997; Kripalani and Kulkarni 1997, 1998; Zveryaev and Aleksandrova 2004; Limsakul et al. 2010). The thermal states of the ICP can affect the establishment and maintenance of the South China Sea (SCS) summer monsoon (Xu et al. 2002; Zhang and Qian 2002; Wen et al. 2004). The monsoon precipitation over the ICP influences the onset, peak, and withdrawal of monsoon 
rainfall in East Asia (Wang and LinHo 2002). Thus, it is essential to reveal the factors of precipitation variations in the ICP for understanding the climate variability over the adjacent regions. Being one of the strongest signals in short-term climate variability, El Niño-Southern Oscillation (ENSO) contributes to the interannual variation of precipitation over the ICP and surrounding regions. Chen and Yoon (2000) suggested that the ICP summer monsoon rainfall is highly associated with the Niño-3 sea surface temperature (SST). Ge et al. (2017) indicated that the rainy season precipitation over the ICP is related to SST in the tropical central-eastern Pacific during the preceding winter, whereas its correlation with simultaneous SST is weak. Kripalani and Kulkarni (1997) noted that the impact of El Niño (La Niña) on rainfall over Southeast Asia appears more severe during below normal (above normal) rainfall epochs. Zveryaev and Aleksandrova (2004) obtained a positive correlation of the Southeast Asian monsoon rainfall with SST in the north Indian Ocean and the SCS in the previous January-February.

Previous studies identified the relation of regional rainfall in the ICP to tropical Indo-Pacific SST. The Thailand summer monsoon rainfall shows a negative relation with the eastern Pacific SST in recent decades (Singhrattna et al. 2005). The Niño-3.4 SST index leads the Thailand rainfall anomalies by 4 months with high rainfall in La Niña events and low rainfall in El Niño events (Limsakul et al. 2007; Limsakul and Singhruck 2016; Kirtphaiboon et al. 2014). In addition, the relationship between Thailand precipitation and ENSO is modulated by the Pacific decadal oscillation (Limsakul and Singhruck 2016). Nguyen et al. (2007) showed that the October-November rainfall in central Vietnam is correlated with the Pacific SST from one to three months in advance and associated with the Indian Ocean SST from one to two months in advance. The interannual variation of October-November rainfall in central Vietnam is out of phase with the central-eastern Pacific SST anomalies (Yen et al. 2011; Chen et al. 2012). Nguyen et al. (2014) showed that the relationship of Vietnam's temperature and rainfall variability to ENSO is stronger in lower latitudes and in winter.

The ICP rainy season precipitation variation is associated with two types of processes. One is the large-scale circulation change associated with the Indo-Pacific SST anomalies. Interannual variation of the ICP monsoon rainfall is attributed to the divergent circulation induced by tropical Pacific SST anomalies (Chen and Yoon 2000; Singhratttna et al. 2005; Limsakul et al. 2007; Yen et al. 2011). Strong convective activities are maintained by the convergence between anomalous southwesterly winds over the Indian Ocean and northeasterly winds over the
SCS, which are induced by anomalous Walker circulation and local Hadley circulation associated with La Niña (Zhang et al. 2002). The other is westward-propagating disturbances from the SCS and western tropical Pacific, including tropical cyclones, tropical depressions, tropical storms, and submonthly disturbances, that bring rainfall to the ICP. The interannual modulation of the frequency of occurrence and track of these westward-propagating disturbances contributes to rainfall variation over the ICP (Chen and Yoon 2000; Takahashi and Yasunari 2008; Chen et al. 2012; Takahashi et al. 2015; Ge et al. 2017).

Compared to the Indian and East Asian region, the precipitation variability and the factors in the ICP region have been much less investigated. The majority of previous studies on the ICP rainfall variability have focused on the relationship between the interannual variation of precipitation over an area or a country of the ICP and the SST anomalies of the Pacific Ocean. Most previous studies did not distinguish the influences of SST anomalies on rainfall over the ICP in different periods of the rainy season. There is a lack of analysis of the individual and combined roles of SST anomalies in different regions in the ICP rainfall variability. This study aims to conduct a systematic analysis of the tropical Indo-Pacific SST impacts on the rainfall variability in the whole ICP region. We distinguish the relationship between the tropical Indo-Pacific SST anomalies and the ICP precipitation variation in different periods of the rainy season. We also analyze the individual and combined effects of SST anomalies in different regions on interannual variation of precipitation over the whole ICP.

The rest of this paper is organized as follows. Section 2 describes the datasets and analysis methods used in this study. Section 3 analyzes interannual variations of precipitation over the ICP. An analysis of lead-lag relationship to tropical Indo-Pacific SST anomalies is presented in section 4 . Section 5 documents the individual and coherent roles of SST anomalies in different regions in precipitation variation over the ICP. Section 6 presents results of numerical experiments to confirm the contributions of regional SST anomalies. Section 7 gives a summary and discussion.

\section{Data and methods}

The Global Precipitation Climatology Centre (GPCC) dataset (Becker et al. 2013) is used in this study to analyze the precipitation distribution and variation in the ICP region. This dataset (available at https://www.esrl.noaa. gov/psd/), covers the global land and spans the period from January 1979 to December 2016. The $0.5^{\circ} \times 0.5^{\circ}$ grid data are selected for this analysis. This study also uses the Global Precipitation Climatology Project (GPCP), 

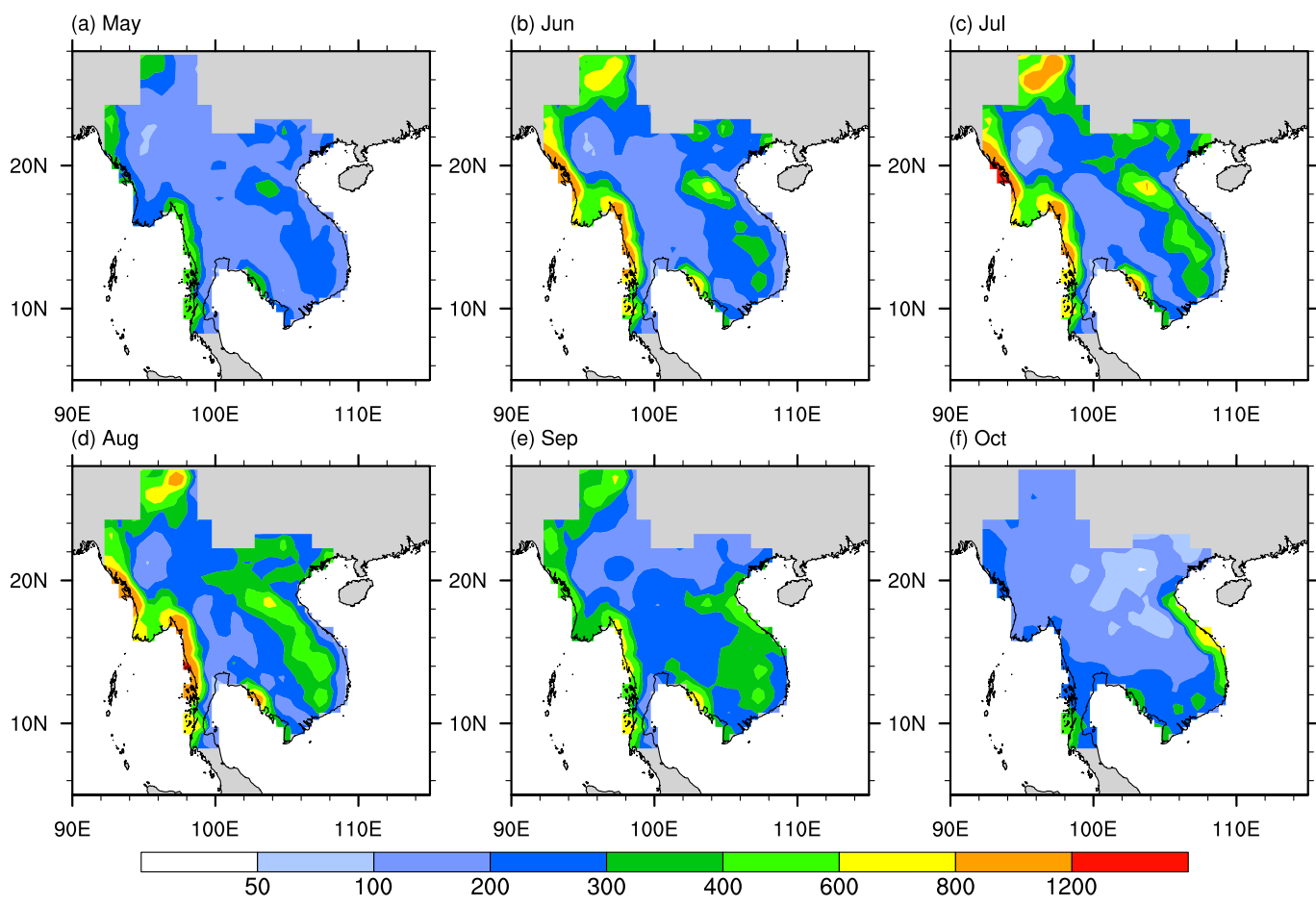

(e) Sep
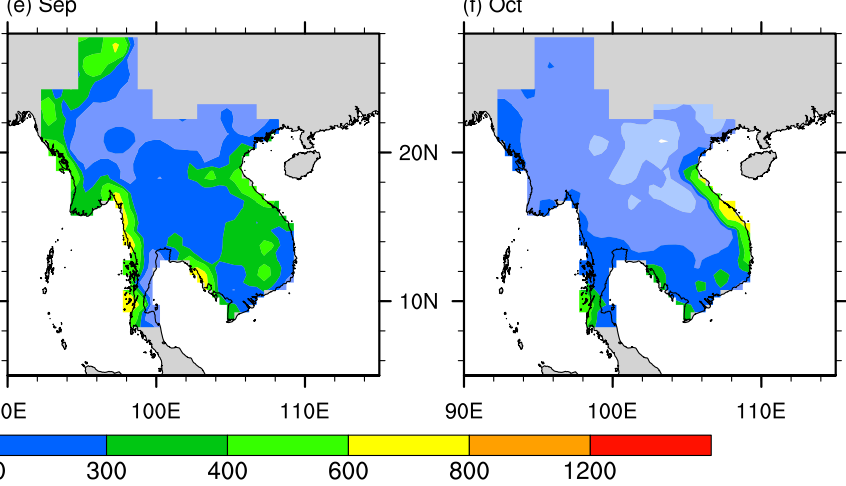

FIG. 1. Climatological monthly precipitation ( $\mathrm{mm}$; shading) over the ICP during the rainy season for the period 1979-2016.

version 2.3, monthly precipitation dataset (available from http://www.esrl.noaa.gov/psd/; Adler et al. 2003). This dataset has a resolution of $2.5^{\circ} \times 2.5^{\circ}$ and is available starting from January 1979.

We use the atmospheric wind data from the European Centre for Medium-Range Weather Forecasts (ECMWF) interim reanalysis (ERA-Interim; Dee et al. 2011). The $0.5^{\circ} \times 0.5^{\circ}$ grid and monthly mean wind data of ERAInterim dataset are selected for this analysis, and it covers the period from January 1979 to present (available online at https://www.ecmwf.int/).

This study also uses SST from the Met Office Hadley Centre Sea Ice and Sea Surface Temperature, version 1.1 (HadISST 1.1; Rayner et al. 2003). The HadISST dataset is available on a $1.0^{\circ} \times 1.0^{\circ}$ grid from 1870 to the present (available online at https://www.metoffice.gov. uk/hadobs/hadisst/).

The present study conducts numerical experiments with the atmosphere component of the Community Earth System Model (CESM). CESM is a fully coupled, community, global climate model developed by the National Center for Atmospheric Research (NCAR) (Hurrell et al. 2013; Kay et al. 2015). Composed of separate components simultaneously simulating Earth's atmosphere, ocean, land, land ice, and sea ice, plus one central coupler component, CESM allows researchers to conduct fundamental research into Earth's past, present, and future climate states (http://www.cesm.ucar.edu/models/ cesm1.1/cesm/doc/usersguide/book1.html). We use the Community Atmosphere Model version 5.2 (CAM5.2; http://www.cesm.ucar.edu/models/cesm1.1/cam/docs/ug5_2/ book1.html). This study uses finite-volume grids at a horizontal resolution of $1.9^{\circ}$ latitude by $2.5^{\circ}$ longitude and with 30 vertical levels.

The present analysis focuses on interannual variations. Harmonic analysis is applied to extract interannual variations with time period shorter than 10 years for all the variables. All analyses of the correlation, regression, area averaging, composite, and empirical orthogonal function (EOF) are applied based on interannual anomalies. The statistical significance of correlation, regression, and composite anomalies is determined based on the Student's $t$ test. The present analysis focuses on the time period 1979-2016 when all the variables are available.

\section{Characteristics of interannual variation of precipitation}

Climatologically, most of the ICP experiences the rainy season from May to October (Yang and Wu 2019). During May-August, rainfall is mainly concentrated along the west coast and near the mountains in the eastern ICP (Fig. 1). The amount of rainfall in these regions increases from May to August (Figs. 1a-d) and 

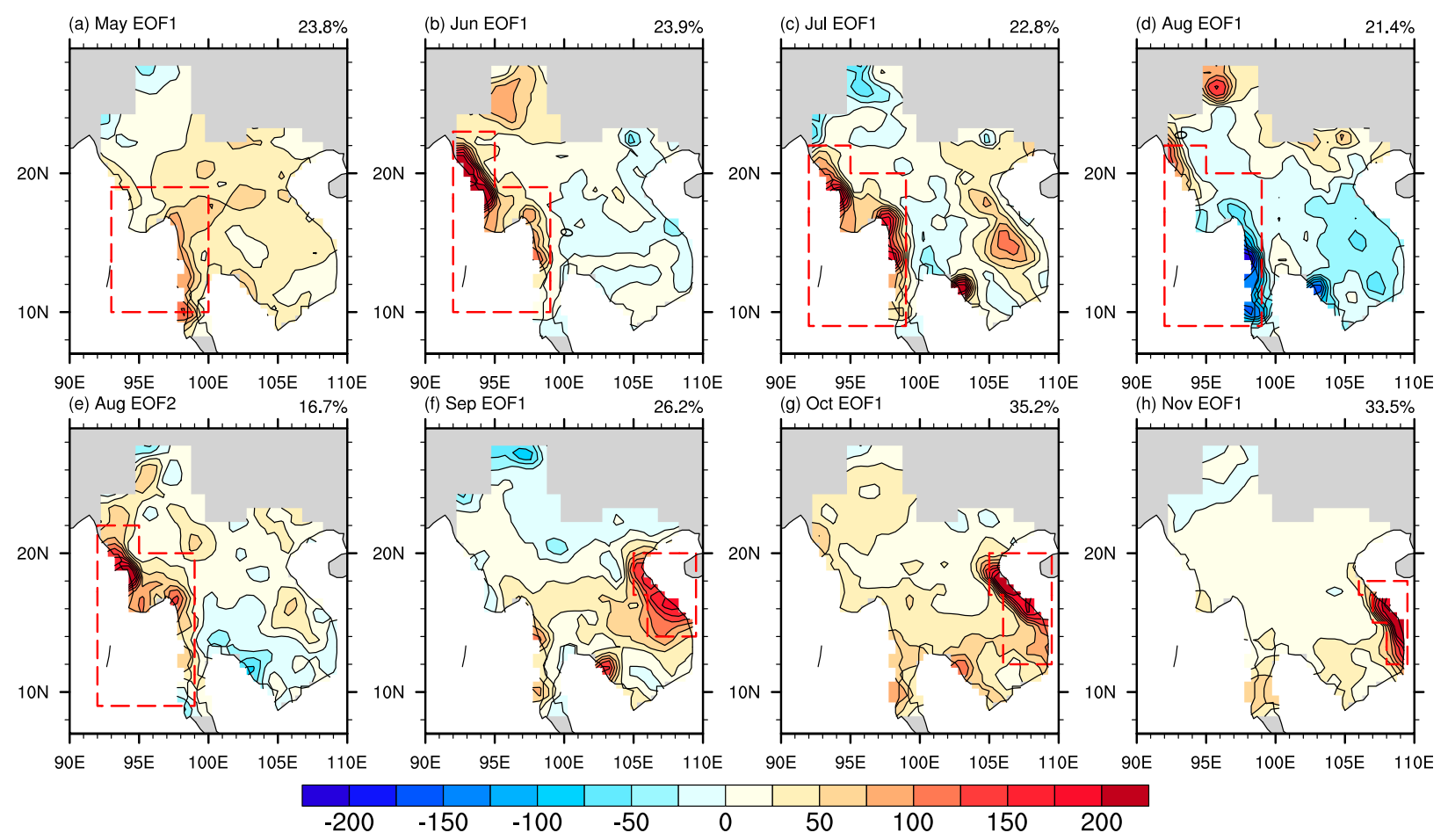

FIG. 2. Spatial patterns of the (a)-(d),(f)-(h) first and (e) second EOF modes of monthly precipitation anomalies (mm; shading) over the ICP for the period 1979-2016. The red-outlined boxes denote the regions used for calculation of area-mean precipitation in Tables 1 and 2. The value on the top right of each panel is the percent variance explained by the corresponding mode.

turns to a decrease after August (Figs. 1e-f). Large rainfall appears along the east coast of Vietnam in September and October (Figs. 1e-f) and remains in November (not shown). As the rainfall variability in November shows similar features to that in October, the interannual variation of November rainfall is also included in the present analysis. So, the rainy season over the ICP covers the months from May to November in the present study.

An EOF analysis is applied to monthly precipitation anomalies to unravel the leading modes of interannual precipitation variation over the ICP. The percent variance accounted for by the leading two modes is $23.8 \%$ and $18.6 \%$ in May, $23.9 \%$ and $10.4 \%$ in June, $22.8 \%$ and $18.1 \%$ in July, $21.4 \%$ and $16.7 \%$ in August, $26.2 \%$ and $14.1 \%$ in September, $35.2 \%$ and $11.2 \%$ in October, and $33.5 \%$ and $15.7 \%$ in November. According to the method of North et al. (1982), the first mode is separable from the second mode in June, September, October, and November. Figure 2 shows the spatial patterns of the first EOF modes in May through November and the second EOF mode in August over the ICP. The leading modes in May and June have large loading along the west coast (Figs. 2a,b). The leading mode in July and the second mode in August display large loading along the west coast and over the eastern part (Figs. 2c,e). The coexistence of large loading along the west coast and over the eastern mountainous region indicates that the interannual variations of precipitation over the ICP are likely controlled by large-scale wind changes whose effects are enhanced locally due to orography. The leading mode in September, October and November has large loading along the east coast (Figs. 2f-h). The leading mode in August displays a north-south opposite loading over most part of the ICP (Fig. 2d). So does the second mode in May, June, and July.

The correlation coefficients between the normalized principal component (PC) time series and normalized area-mean monthly precipitation anomalies are shown in Table 1. The domains for averaging monthly precipitation anomalies are indicated by boxes in Figs. $2 \mathrm{a}-\mathrm{h}$, which are determined by the distribution of loading in respective month. Apparently, the year-to-year variations of area-mean precipitation anomalies are very similar to those of the corresponding principal component time series of PC1 (PC2 in August). The correlations between the area-mean precipitation anomalies and corresponding PCs are higher than 0.85 . This illustrates that the leading modes (PC1) in the rainy season (except for August) and the second mode (PC2) in August represent well the main characteristics of interannual variations of rainfall in the region of large 
TABLE 1. The correlation coefficients between PCs and areamean precipitation anomalies (aave) in the red box in Fig. 2 of every month in the rainy season over the ICP.

\begin{tabular}{cccccccc}
\hline \hline Month & May & Jun & Jul & Aug & Sep & Oct & Nov \\
\hline $\begin{array}{c}\text { PC and aave } \\
\text { correlation }\end{array}$ & 0.92 & 0.93 & 0.94 & 0.86 & 0.96 & 0.95 & 0.97 \\
\hline
\end{tabular}

variability. It is noted that large loading appears along the west coast and over the eastern mountainous region in July and August. We examined the relation between area-mean precipitation along the west coast and over the eastern mountainous region around the Annam Mountain. The correlation coefficient is 0.54 in July and 0.4 in August, which pass the $95 \%$ confidence level. This suggests that precipitation variation tends to be in phase along the west coast and over the eastern mountainous region in July and August.

We have analyzed the lead-lag correlation of monthly Niño-3.4 SST anomaly with PC2 of May, June, and July and $\mathrm{PC} 1$ of August. It turns out that the correlation with PC2 in May and PC1 in August displays a similar temporal evolution, with significant negative correlation coefficient during concurrent summer to the succeeding spring (not shown). The Indo-Pacific SST correlation features a westeast contrast with positive value in the tropical southeastern Indian Ocean and the tropical western Pacific and negative value in the equatorial central-eastern Pacific during concurrent summer to the succeeding spring (not shown). The correlation with $\mathrm{PC} 2$ in June and July is moderately positive during the preceding winter to succeeding winter (not shown). The spatial distribution of SST correlation displays positive value in the equatorial central-eastern Pacific (not shown). The above correlation suggests that the relationship of the north-south distribution of rainfall anomalies over the ICP to the tropical Indo-Pacific SST anomalies may have subseasonal variations, which is worthy of investigation. In the present analysis, we focus on analyzing the leading modes in MayJuly and the second mode in August that display large same-sign loading along the west coast of the ICP and the leading modes in September-November that have large same-sign loading along the east coast of the ICP.

As shown in Table 2, another feature to note is the relationship of rainfall variations in the neighboring months. The correlation coefficient between the PC1 time series in May and June is 0.25 . The correlation coefficient between July PC1 and August PC2 is as high as 0.44 . The correlation coefficient between October and November PC1 is 0.27 . The relationship is weak between PC1s in September and other months. The above results suggest that the rainfall variations have certain
TABLE 2. The correlation coefficient of corresponding PCs and area-mean precipitation anomalies (aave) in the red box in Fig. 2 between two neighboring months that show a similar spatial and temporary variation.

\begin{tabular}{lccc}
\hline \hline $\begin{array}{c}\text { Neighboring } \\
\text { months }\end{array}$ & May and Jun & Jul and Aug & Oct and Nov \\
\hline PCs correlation & 0.25 & 0.44 & 0.27 \\
aave correlation & 0.35 & 0.71 & 0.27 \\
\hline
\end{tabular}

similarity in two neighboring months, such as May-June, July-August, and October-November. The correlation coefficients based on area-mean precipitation confirm the above results.

\section{Lead-lag relationship with tropical Indo-Pacific SST}

The relationship of interannual variation of rainfall over the ICP to ENSO depends on the period of the rainy season. Figure 3a shows the lead-lag correlation of monthly Niño-3.4 SST with PC1 in May, July, and October in the rainy season. Figure $3 b$ is similar to Fig. $3 a$ except for area-mean rainfall anomalies in respective months. The SST anomaly averaged over the Niño-3.4 region $\left(5^{\circ} \mathrm{S}-5^{\circ} \mathrm{N}, 170^{\circ}-120^{\circ} \mathrm{W}\right)$ is used as an index for ENSO. Note that year (0) indicates the same year of the rainy season, and year $(-1)$ and year $(+1)$ denote the previous year and the following year, respectively.
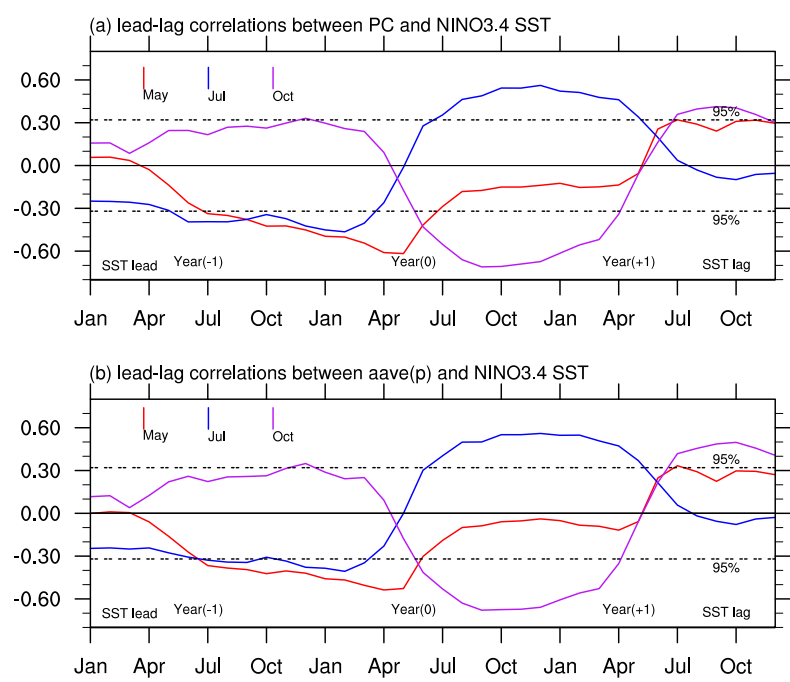

FIG. 3. Lead-lag correlation of (a) PC1 in and (b) area-mean precipitation anomalies over the regions denoted by the boxes in Fig. 2 in May, July, and October with monthly Niño-3.4 SST. The horizontal dashed lines denote the $95 \%$ confidence level of the correlation coefficient. 
As shown in Fig. 3a, the correlation of Niño-3.4 SST with $\mathrm{PC} 1$ in May is negative from preceding summer to the concurrent month with the value of the correlation coefficient passing the $95 \%$ confidence level. The correlation with PC1 in June is negative from preceding summer to the concurrent month with a smaller magnitude compared to that in May (not shown). The correlation with PC1 in July is negative from the preceding summer to concurrent spring and positive during the concurrent summer to succeeding spring. The value of the correlation coefficient in concurrent summer to succeeding winter passes the $95 \%$ confidence level. The correlation with PC2 in August displays a temporal variation similar to that in July but with a smaller magnitude during concurrent spring to winter (not shown). The temporal variation of correlation with PC1 in September appears similar to that in July and August, but with a much smaller value of correlation coefficient (not shown). The correlation with PC1 in October and November (not shown) has a similar temporal variation with positive value from preceding summer to concurrent spring and negative value during concurrent summer to succeeding spring. The negative correlation during concurrent summer to succeeding winter is large, passing the $95 \%$ confidence level. In comparison, the correlation is larger with PC1 in October than in November during concurrent summer and fall. The temporal evolutions of correlation with area-mean rainfall anomalies in respective months (Fig. 3b) confirm most of the above features. In July and August, the lead-lag correlations of area-mean precipitation along the west coast and over the eastern mountainous region with the Niño-3.4 SST anomalies are consistent with the correlation of PC with the correlation coefficient passing the $95 \%$ confidence level from concurrent summer to succeeding winter.

The above results indicate that rainfall over the ICP tends to be above normal in May-June of the La Niña decaying year, in July-August of the La Niña decaying year and/or the El Niño developing year, and in OctoberNovember of the La Niña developing year. The lead-lag relationship between the ICP rainfall and the Pacific SST is in line with previous studies (Chen and Yoon 2000; Singhrattna et al. 2005; Kirtphaiboon et al. 2014; Limsakul and Singhruck 2016; Ge et al. 2017). Some previous studies pointed out that the rainy season precipitation of the ICP has a weak correlation with simultaneous Niño-3.4 SST (Takahashi et al. 2015; Ge et al. 2017). This may be due to the fact that they did not separate the May-June and July-August precipitation in their analysis.

To further understand the relationship between interannual precipitation variation over the ICP in the rainy season and tropical Indo-Pacific SST, we examine lead-lag regression of bimonthly SST and $10-\mathrm{m}$ winds from preceding winter to concurrent fall onto $\mathrm{PC} 1$ in May (Fig. 4), July (Fig. 5), and October (Fig. 6), respectively. As shown above, the relationship of SST to PC1 in June is similar to PC1 in May, the relationship of SST to PC2 in August is similar to PC1 in July, and the relationship of SST to PC1 in November is similar to $\mathrm{PC} 1$ in October. As such, we do not show figures of SST with PC1 in June, PC2 in August, and PC1 in November.

Corresponding to more rainfall in May, negative SST anomalies are observed in the equatorial central-eastern Pacific along with anomalous lower-level easterlies over the equatorial western-central Pacific in preceding winter (Figs. 4a,b). These SST and wind anomalies weaken during March-April through SeptemberOctober (Figs. 4c-f), indicative of the decay of La Niña events. In the tropical Indian Ocean, negative SST anomalies appear first in the southwest part in preceding November-December (Fig. 4a) and then intensify and expand during January through April (Figs. 4b,c). A north-south gradient of SST anomalies is seen in March-April (Fig. 4c), which is accompanied by anomalous cross-equatorial flows (Figs. 4c,d). The asymmetric distribution of SST and wind anomalies over the tropical Indian Ocean has been documented by Wu et al. (2008). Anomalous westerly winds extend from the north Indian Ocean to the WNP in May-June (Fig. 4d). The ICP is under the influence of anomalous lower-level westerlies. The negative SST anomalies decrease in the south Indian Ocean and increase in the north Indian Ocean in May-June (Fig. 4d). The SST anomalies decrease in the tropical Indian Ocean after summer (Figs. 4e,f). Over the WNP, an anomalous cyclone is observed in JanuaryFebruary with warm SST anomalies to its southeast flank (Fig. 4b). Both the wind and SST anomalies in the WNP weaken in the following months (Figs. 4c,d). The temporal evolution of SST and wind anomalies corresponding to June precipitation is similar to that corresponding to May precipitation but SST and wind anomalies seem weaker (not shown). We note that the SST anomaly pattern corresponding to May PC1 over the ICP is similar to that with respect to April-June rainfall over the SCS (Hu et al. 2014).

Corresponding to more rainfall in July, the SST anomalies in the equatorial Pacific feature a switch from negative in preceding winter to positive in concurrent summer (Fig. 5). This is accompanied by a switch of lower-level wind anomalies from easterly to westerly over the equatorial center Pacific. This indicates a transition from La Niña events to El Niño events. Over the tropical Indian Ocean, lower-level wind anomalies change from westerly in preceding winter to southeasterly in summer 
(a) NovDec SSTuv10 \& May PC1

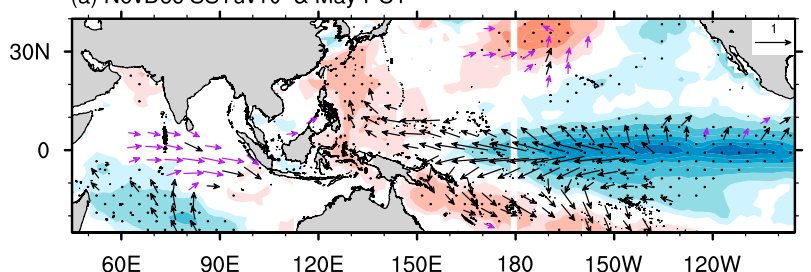

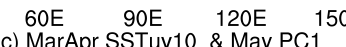

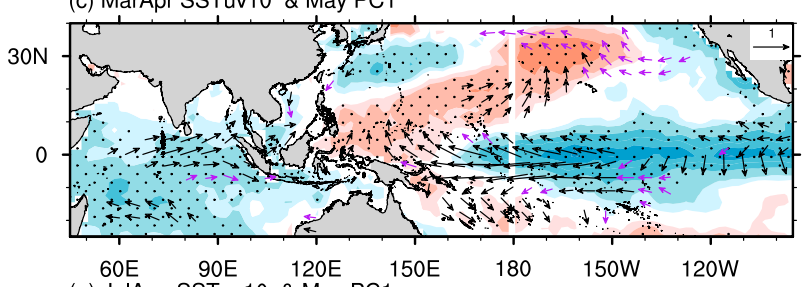

$60 \mathrm{E}$
(e) JulAug SSTuv10 \& May PC1

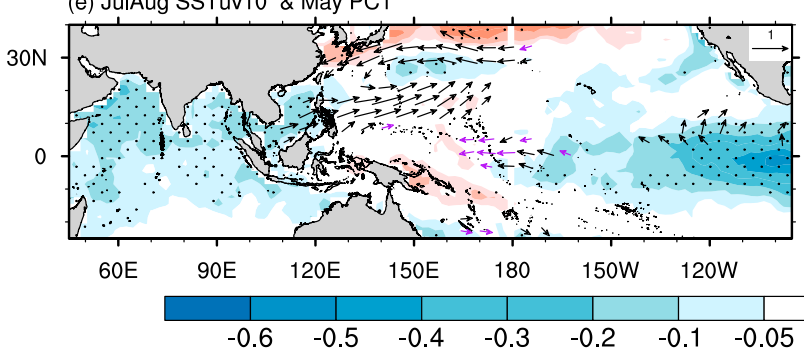

(b) JanFeb SSTuv10 \& May PC1

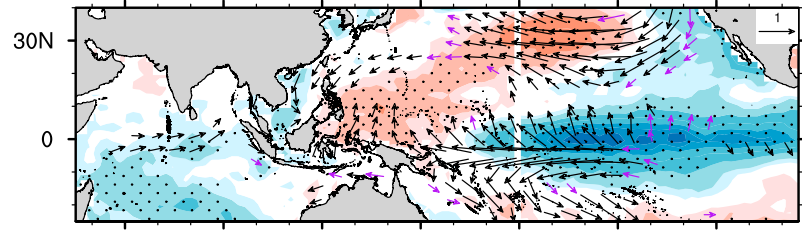

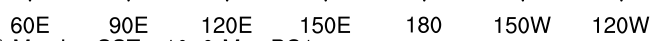

(d) MayJun SSTuv10 \& May PC1

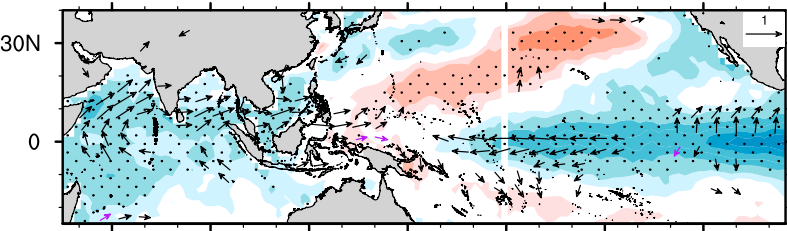

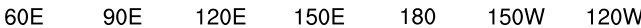

(f) SepOct SSTuv10 \& May PC1

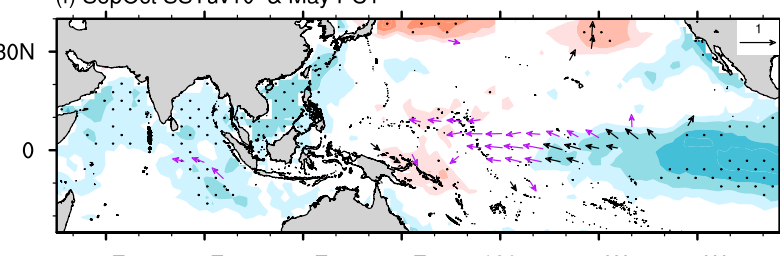

FIG. 4. Lead-lag regression of bimonthly anomalies of SST $\left({ }^{\circ} \mathrm{C}\right.$; shading) and $10-\mathrm{m}$ wind $\left(\mathrm{m} \mathrm{s}^{-1}\right.$; vectors. the scale is at the top-right corner) from the preceding winter to concurrent autumn onto May PC1. Dotted areas denote that SST anomalies are significant at the 95\% confidence level. Wind vectors in black denote that wind anomalies are significant at the 95\% confidence level. Wind vectors in purple denote that the magnitude of wind anomalies is larger than $0.3 \mathrm{~m} \mathrm{~s}^{-1}$ but not reaching the $95 \%$ confidence level.

and fall, accompanying the development of negative SST anomalies in the tropical southeastern Indian Ocean. In concurrent summer (Fig. 5e), cross-equatorial flows from the tropical southeastern Indian Ocean turn to westerlies over the north Indian Ocean and the SCS. Thus, the ICP is under the influence of anomalous lower-level westerlies. The SST and wind anomalies corresponding to PC2 in August (not shown) resemble closely those corresponding to $\mathrm{PC} 1$ in July. Although the distribution of SST and wind anomalies corresponding to PC1 in September (not shown) is similar to that corresponding to PC1 in July, the SST and wind anomalies are much weaker. We note that the distribution of SST anomalies corresponding to July PC1 resembles that with respect to the leading mode of summer rainfall over the SCS (He and $\mathrm{Wu} 2014$ ).

Corresponding to more rainfall in October, moderate positive SST anomalies are observed in the equatorial central-eastern Pacific in preceding winter, accompanied by anomalous lower-level westerlies (Figs. 6a,b). The SST anomalies become negative in May-June and intensify in summer and fall with large anomalous lower-level easterlies covering the equatorial westerncentral Pacific (Figs. 6c-f). These features illustrate the development of La Niña events. In fall, anomalous lower-level easterly winds dominate the western tropical Pacific (Fig. 6f). Meanwhile, negative SST anomalies appear in the tropical western Indian Ocean, forming an east-west dipole SST anomaly pattern with positive SST anomalies in the tropical southeast Indian Ocean. Anomalous lower-level westerlies span the tropical Indian Ocean. The ICP lies in a region of anomalous lower-level convergence. The SST and wind anomalies corresponding to PC1 in November (not shown) are very similar to those corresponding to $\mathrm{PC} 1$ in October. The above results agree with previous studies (Yen et al. 2011; Chen et al. 2012).

\section{Respective and combined impacts of regional SST anomalies}

Analysis in the previous section reveals that the ICP rainfall variations are associated with tropical IndoPacific SST anomalies in several regions. In this section, composite analysis is performed to document the impacts of individual and combined SST anomalies on the ICP precipitation in May, July, and October. We first analyze the difference of anomalies in positive and negative rainfall years. Then, we compare the anomalies among years with different combinations of regional 
(a) NovDec SSTuv10 \& Jul PC1

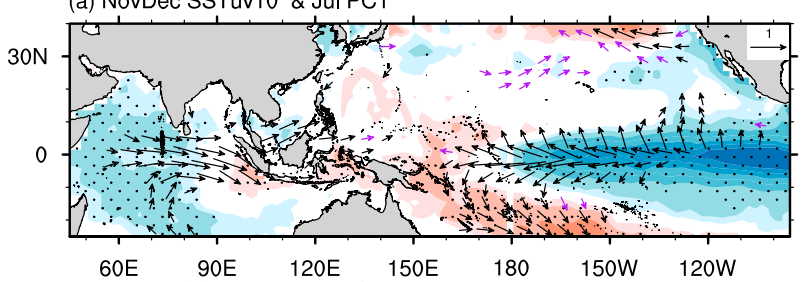

(c) MarApr SSTuv10 \& Jul PC1

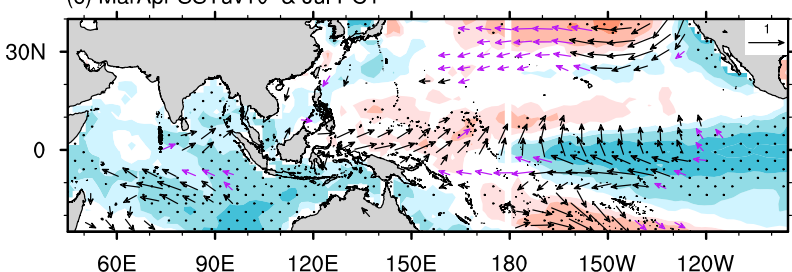

$\begin{array}{lllllll}60 \mathrm{E} & 90 \mathrm{E} & 120 \mathrm{E} & 150 \mathrm{E} & 180 & 150 \mathrm{~W} & 120 \mathrm{~W}\end{array}$

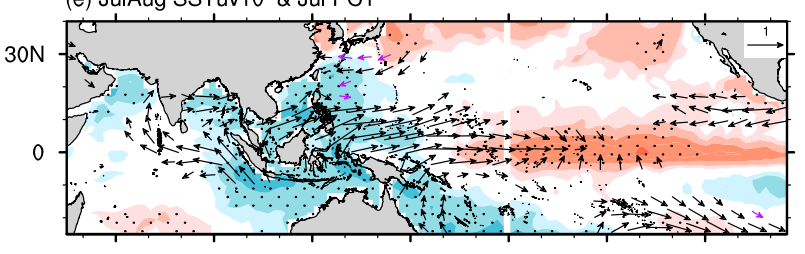

$60 \mathrm{E}$

$90 \mathrm{E} \quad 120 \mathrm{E} \quad 150 \mathrm{E} \quad 180 \quad 150 \mathrm{~W} \quad 120 \mathrm{~W}$ (b) JanFeb SSTuv10 \& Jul PC1

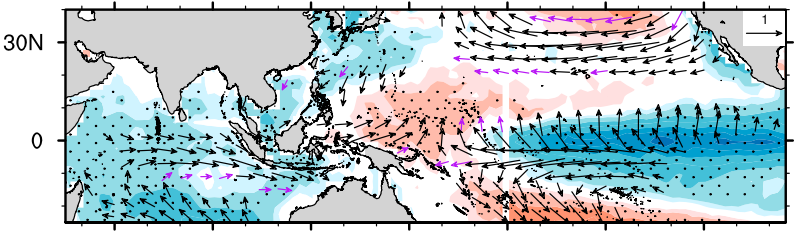

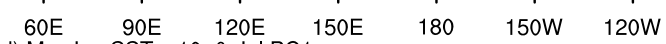

(d) MayJun SSTuv10 \& Jul PC1

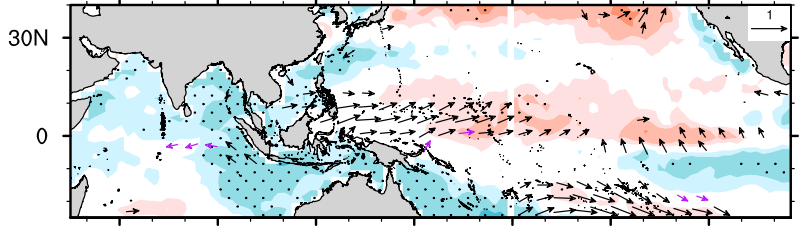

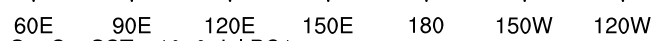

(f) SepOct SSTuv10 \& Jul PC1

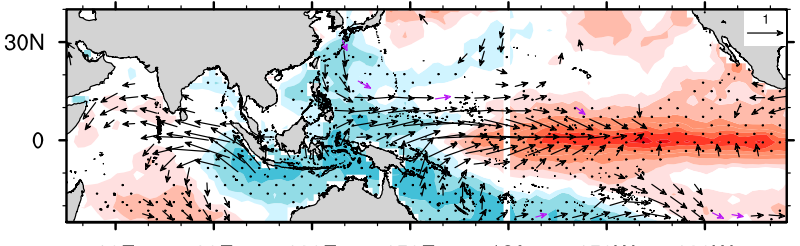

$\begin{array}{lllllll}60 \mathrm{E} & 90 \mathrm{E} & 120 \mathrm{E} & 150 \mathrm{E} & 180 & 150 \mathrm{~W} & 120 \mathrm{~W}\end{array}$

FIG. 5. As in Fig. 4, but onto July PC1.

SST anomalies. Composite anomalies are obtained for anomalous May, July, and October rainfall years, respectively.

\section{a. Characteristics of anomalies in May, July, and October}

The normalized time series of PC1 in May, July, and October are used to obtain anomalous precipitation years. Similar results are obtained when using areamean rainfall anomalies. The 0.5 standard deviation of time series is used as a criterion to determine an anomalous year of precipitation. According to this criterion, there are 10 positive and 12 negative May rainfall anomaly years, 13 positive and 13 negative July rainfall anomaly years, and 12 positive and 9 negative October rainfall anomaly years, respectively, during 1979-2016. Figure 7 shows the difference of composite anomalies of precipitation, SST, and $10-\mathrm{m}$ and $200-\mathrm{hPa}$ winds between positive and negative rainfall years.

In May, significant positive precipitation anomalies dominate the ICP, SCS, and WNP, and negative rainfall anomalies are located over the tropical Indian Ocean and equatorial central Pacific (Fig. 7a). Anomalous lower-level westerlies extend from the north Indian Ocean to the WNP (Fig. 7b). The anomalous westerlies weaken when they reach the west coast of the ICP, leading to anomalous lower-level convergence. Meanwhile, anomalous diverging winds control the ICP in the upper troposphere (Fig. 7a). There are positive SST anomalies in the WNP and negative SST anomalies in the south Indian Ocean and equatorial central-eastern Pacific (Fig. 7b). The positive relationship between local precipitation and SST anomalies indicates local SST forcing of precipitation in these regions (Wu et al. 2006; $\mathrm{Wu}$ and Kirtman 2007). The negative equatorial central Pacific SST anomalies contribute to rainfall increase over the ICP through anomalous Walker circulation (Chen and Yoon 2000; Singhrattna et al. 2005; Limsakul et al. 2007). The warm WNP SST anomalies contribute to anomalous lower-level westerlies through a Rossby wave-type response (Wu et al. 2014). The negative SST anomalies in the south Indian Ocean contribute to anomalous lower-level westerlies over the north Indian Ocean through the SCS through cross-equatorial flows (Hu et al. 2014). Considering the local SST forcing of precipitation, we define three regions with significant SST anomalies: the south Indian Ocean (SIO), WNP, and equatorial central-eastern Pacific (EP), respectively (red boxes in Fig. 7b). The individual and combined effects of SST anomalies in the above regions on the ICP May rainfall will be analyzed in section $5 \mathrm{~b}$. Note that the negative SST anomalies in the north Indian Ocean appear as a result of a cloud increase-induced decrease in downward shortwave radiation and wind speed increaseinduced enhancement in upward latent heat flux accompanying more rainfall there. 
(a) NovDec SSTuv10 \& Oct PC1

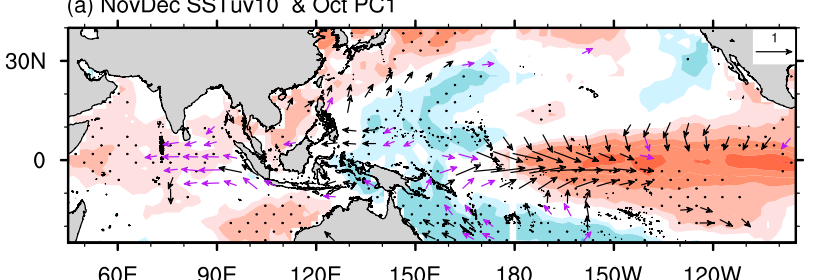

60E
(c) MarApr SSTuv10 \& Oct PC1

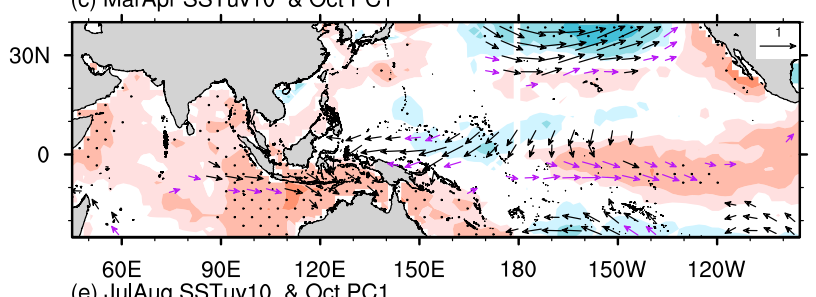

(e) JulAug SSTuv10 \& Oct PC1

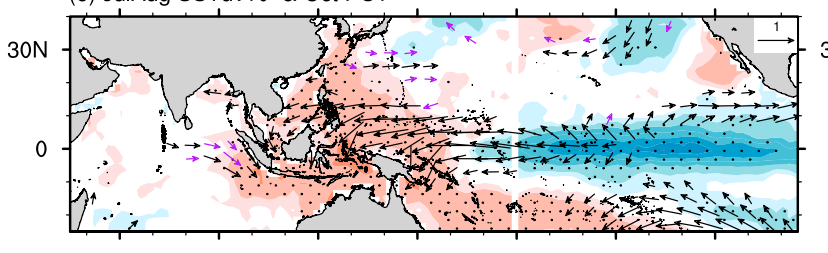

$60 \mathrm{E}$

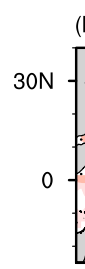

(b) JanFeb SSTuv10 \& Oct PC1

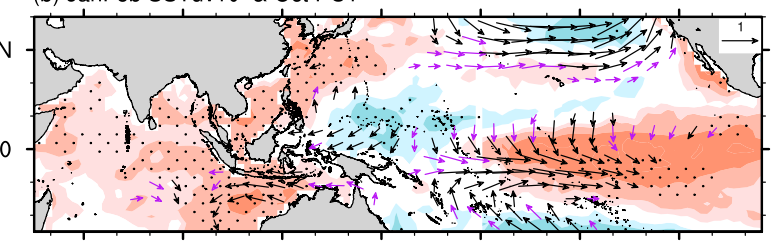

$\begin{array}{llllll}60 \mathrm{E} & 90 \mathrm{E} & 120 \mathrm{E} \quad 150 \mathrm{E} \quad 180 \quad 150 \mathrm{~W} & 120 \mathrm{~W}\end{array}$
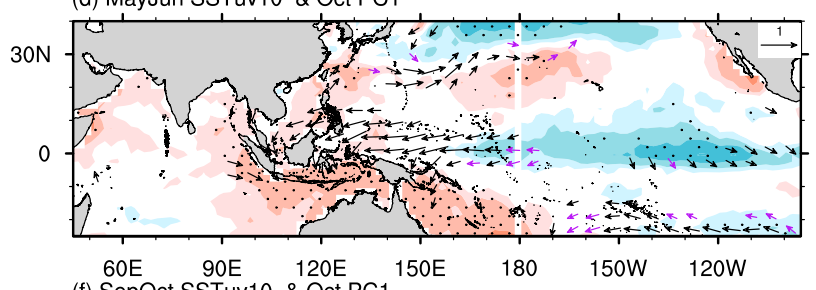

$30 \mathrm{~N}$

(f) SepOct SSTuv10 \& Oct PC1

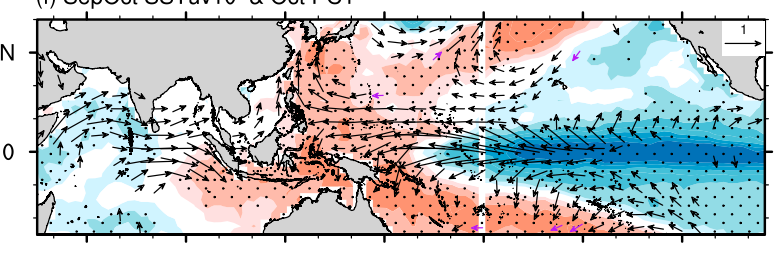

$-0.6$

$\begin{array}{lll}-0.5 & -0.4 & -0.3\end{array}$

FIG. 6. As in Fig. 4, but onto October PC1.

In July, positive rainfall anomalies appear over the west coast and the eastern mountainous region of the ICP, southern China, and the WNP and negative rainfall anomalies extend from the "Maritime Continent" to southern India (Fig. 7c). The ICP is dominated by anomalous lower-level westerlies (Fig. 7d). The slowdown of these westerlies when they hit the coast of the ICP leads to anomalous lower-level convergence. At the upper troposphere, anomalous anticyclonic winds cover the ICP and SCS (Fig. 7c). There are positive SST anomalies in the equatorial central Pacific and negative SST anomalies in the tropical southeast Indian Ocean (Fig. 7d). The positive relationship between local SST and precipitation anomalies in the equatorial central Pacific and tropical southeast Indian Ocean indicates local SST forcing of precipitation in these regions. The impacts of the warm equatorial central Pacific SST anomalies on the ICP rainfall may be interpreted as a westward extension of the Rossby wave response. The impacts of the cold southeast Indian Ocean SST anomalies may be through an anomalous cross-equatorial overturning circulation (Wu et al. 2012; Wu and He 2017). Accordingly, we define two key SST regions: the equatorial central Pacific (ECP) and tropical southeast Indian Ocean (SEIO) (red boxes in Fig. 7d). The individual and combined effects of SST anomalies in the above two regions on the ICP July rainfall will be further analyzed in section $5 \mathrm{c}$.
In October, positive rainfall anomalies cover the ICP, SCS, and the Maritime Continent (Fig. 7e). Negative rainfall anomalies are observed over the equatorial central Pacific and the tropical western Indian Ocean. Anomalous lower-level westerly winds extend from the western Indian Ocean to the ICP, leading to anomalous lower-level convergence there (Fig. 7f). Vietnam is under the influence of anomalous lower-level northeasterly winds in the north and an anomalous cyclone in the south. The lower-level converging winds lead to rainfall increase there (Fig. 7e). Anomalous divergence at upper troposphere covers the ICP, the SCS, and the Maritime Continent (Fig. 7e), which favors anomalous ascending motion and more precipitation. Negative SST anomalies in the EP and tropical western Indian Ocean (WIO) (red boxes in Fig. 7f) are overlaid by negative rainfall anomalies, indicative of local SST forcing. The impacts of these SST anomalies on the ICP rainfall may be through anomalous Walker circulation (Chen and Yoon 2000). This is indicated by opposite lower-level and upper-level wind anomalies over the tropical IndoPacific Ocean (Figs. 7e,f). We will analyze the individual and combined effects of SST anomalies in the above two regions on the ICP October rainfall in section $5 \mathrm{~d}$. The positive SST anomalies in the SEIO are overlaid by positive rainfall anomalies to the west (Figs. 7e,f), indicative of local SST forcing of atmosphere as well. 


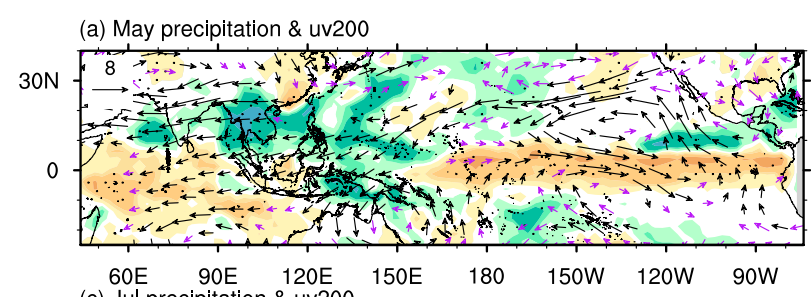

(b) May SST \& uv10m
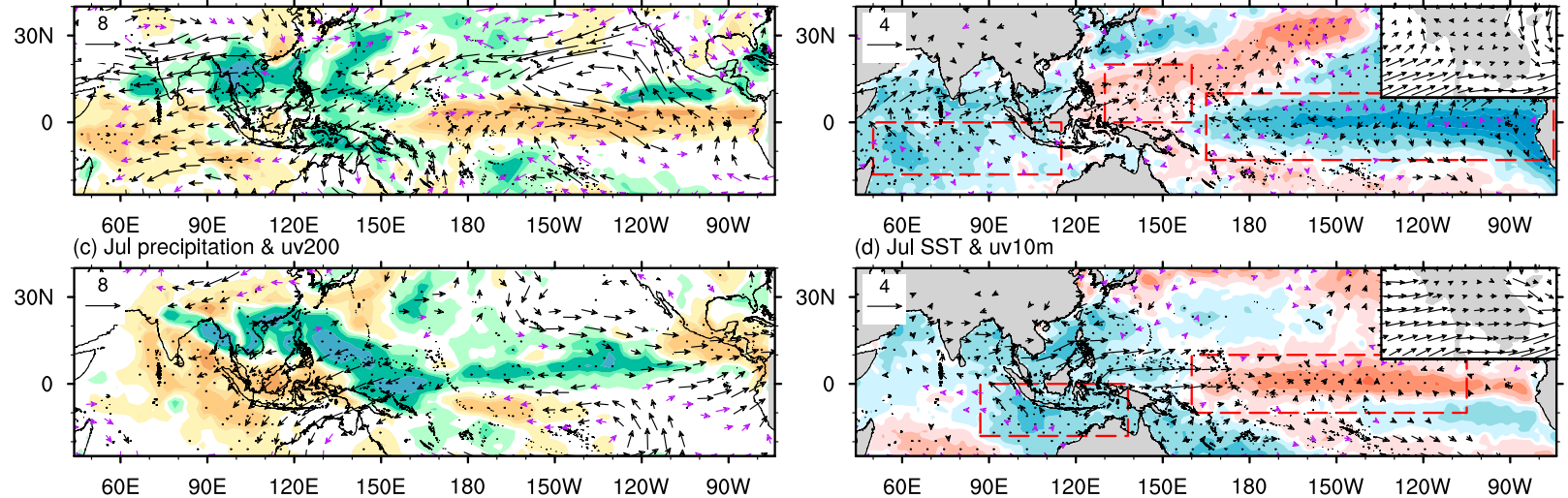

(e) Oct precipitation \& uv200
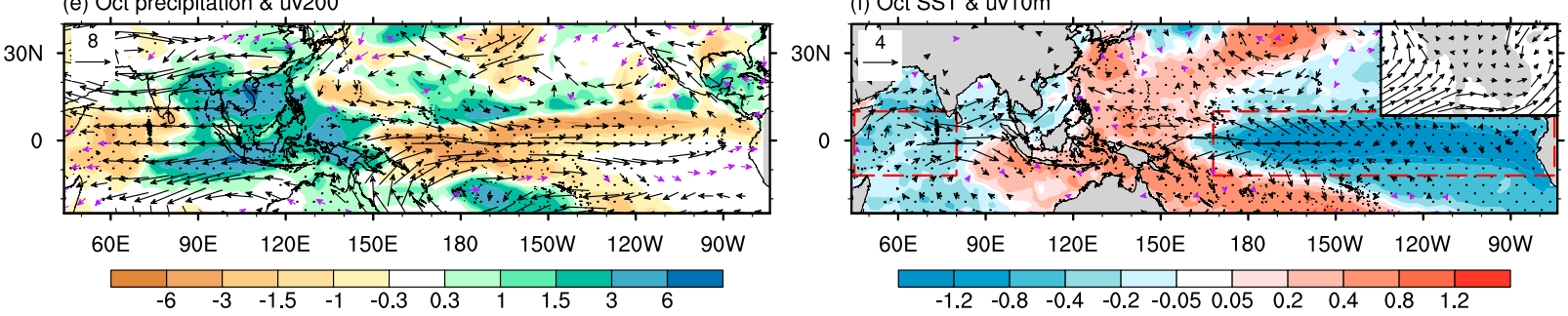

FIG. 7. Composite anomalies of (left) precipitation ( $\mathrm{mm} \mathrm{day}^{-1}$; shading) and $200-\mathrm{hPa}$ wind ( $\mathrm{m} \mathrm{s}^{-1}$; vectors, scale at top-left corner) and (right) SST ( ${ }^{\circ} \mathrm{C}$; shading) and 10-m wind ( $\mathrm{m} \mathrm{s}^{-1}$; vectors, scale at top-left corner) in (a),(b) May, (c),(d) July, and (e),(f) October. Dotted areas denote that the composite precipitation and SST anomalies are significant at the $90 \%$ confidence level. Wind vectors in black denote that wind anomalies are significant at the $90 \%$ confidence level. Wind vectors in purple denote that the magnitude of wind anomalies is larger than $2 \mathrm{~m} \mathrm{~s}^{-1}$ (for 200-hPa winds) or $0.5 \mathrm{~m} \mathrm{~s}^{-1}$ (for 10-m winds) but not reaching the $90 \%$ confidence level. The insets in the top-right corner of (b), (d), and (f) show 10-m winds around ICP.

However, we do not see any signal of influence of anomalous heating there on the ICP rainfall. The positive SST anomalies in the WNP are accompanied by negative rainfall and anticyclonic lower-level wind anomalies, indicating that they are likely a result of atmospheric change.

\section{b. Influence of regional SST anomalies on rainfall variation in May}

To analyze the individual and combined impacts of SST anomalies in key regions, we compare in detail the yearto-year variations of both the normalized $\mathrm{PC} 1$ and areamean SST anomalies in the key regions. Three SST regions are considered for May precipitation. An anomalous SST year is determined when area-mean SST anomalies exceed the 0.5 standard deviation. We distinguish three types of cases in May: 1) the $\mathrm{SIO}+\mathrm{WNP}+\mathrm{EP}$ case in which positive rainfall anomalies occur with negative SIO and EP SST anomalies and positive WNP SST anomalies and negative rainfall anomalies occur with positive SIO and EP SST anomalies and negative WNP SST anomalies, 2) the SIO+EP case in which the WNP SST anomalies are weak, positive rainfall anomalies accompany negative SIO and EP SST anomalies, and negative rainfall anomalies accompany positive SIO and EP
SST anomalies, and 3) the WNP+EP case in which SIO SST is normal, positive rainfall anomalies are associated with EP cooling and WNP warming, and negative rainfall anomalies are associated with EP warming and WNP cooling. The specific years are listed in Table 3. In view of the limited number of years, we reverse anomalies in negative rainfall years and combine them with those in positive rainfall years when constructing the composite. Thus, our analysis only shows features common to both positive and negative rainfall anomaly years and cannot display the asymmetric features between the two types of years.

In the cases with the combined influences of three region SST anomalies, positive rainfall anomalies are seen over the ICP, the SCS, and the WNP (Fig. 8a). Negative rainfall anomalies are observed over the EP. Anomalous lower-level westerlies over the north Indian Ocean lead to anomalous convergence and increase rainfall along the west coast of the ICP (Figs. 8a,b). There is anomalous upper-level divergence over the ICP and the WNP (Fig. 8a), enhancing ascending motion. The processes for influence of SST anomalies in the EP, WNP, and SIO have been discussed in previous a previous section and are not repeated here. The influences of SST anomalies in the three regions are similar to the 
TABLE 3. Years with anomalous rainfall and SST in different types of cases in May, July, and October. The SIO, WNP, and EP domains in May are denoted by boxes in Fig. 7b, those of SEIO and ECP in July are denoted by boxes in Fig. 7d, and those of WIO and EP are denoted by boxes in Fig. 7f. An anomalous rainfall and SST year is determined from the 0.5 standard deviation.

\begin{tabular}{llll}
\hline \hline Month & \multicolumn{1}{c}{ SST type } & \multicolumn{1}{c}{ Positive rainfall } & Negative rainfall \\
\hline May & SIO+WNP+EP & 1994 & $1983,1987,1992,1998,2015$ \\
& SIO+EP & 1979,1999 & 2005,2010 \\
Jul & WNP+EP & 1988 & 1997 \\
& SEIO+ECP & $1982,1991,1997$ & 1996,2010 \\
& ECP & 1986,2009 & $1984,1988,1989$ \\
Oct & SEIO & $1994,1999,2000,2006$ & $1992,1995,1998,2016$ \\
& WIO+EP & $1996,1999,2007,2010,2016$ & $1982,1987,1997,2002,2009$ \\
& EP & 1988,1995 & 1994 \\
\hline
\end{tabular}

results of Hu et al. (2014), who showed the influences of the SIO, WNP, and EP SST anomalies on the SCS rainfall variation during the spring-to-summer transition (April, May, and June).

When the WNP SST anomalies are weak, rainfall and wind anomalies become weak over the WNP and the tropical Indian Ocean (Figs. 8c,d). This change indicates the impact of the WNP SST anomalies. Positive rainfall anomalies are concentrated over the ICP (Fig. 8c). The magnitude of rainfall anomalies appear to increase over the eastern ICP. Over the equatorial Pacific, the wind and rainfall anomalies remain with somewhat decrease in magnitude. This confirms the impacts of SST anomalies there.

Without the role of the SIO SST anomalies, anomalous lower-level winds become weaker over the tropical Indian Ocean (Figs. 8e,f). Positive rainfall anomalies cover the western ICP where anomalous lower-level southerlies appear (Fig. 8f). An anomalous rain belt extends northeastward over the WNP, accompanying (a) May precipitation \& uv200, $\mathrm{SIO}+\mathrm{WNP}+\mathrm{EP}$
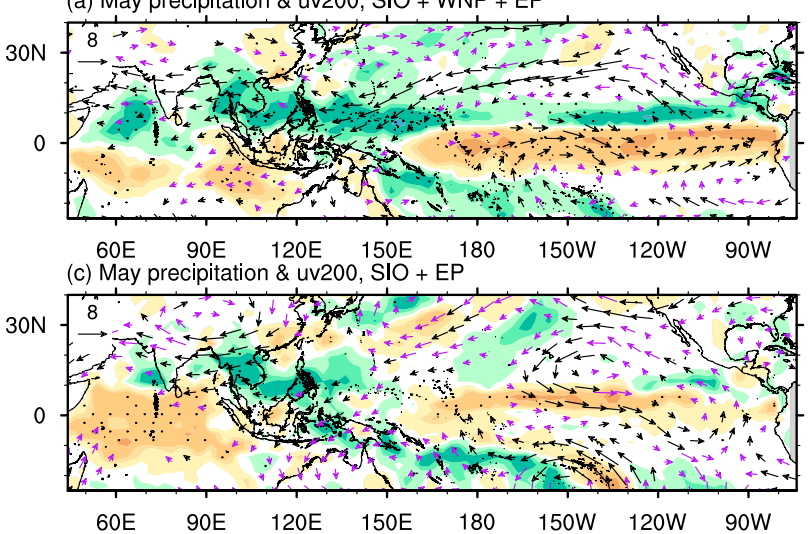

60E $90 \mathrm{E} \quad 120 \mathrm{E} \quad 150 \mathrm{E} \quad 180 \quad 150 \mathrm{~W}$ 120W 90W

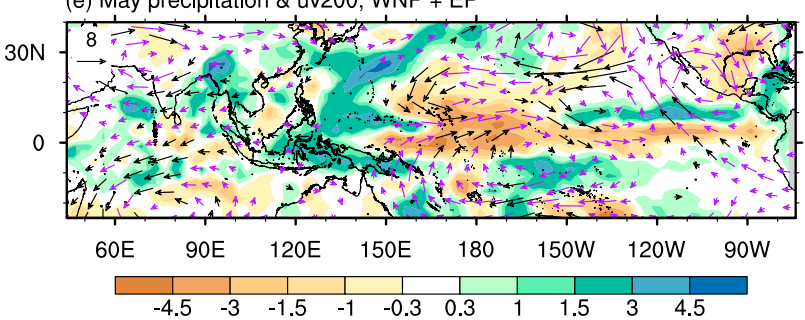

(b) May SST \& uv10m, SIO + WNP + EP

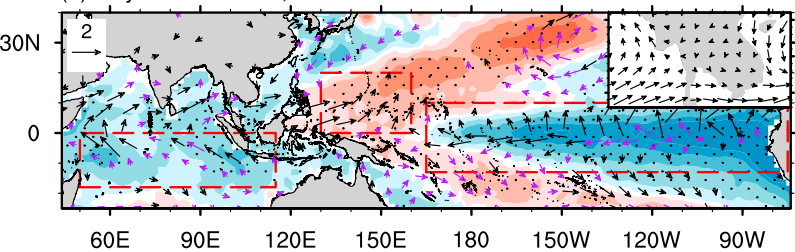

(d) May SST \& uv10m, SIO + EP

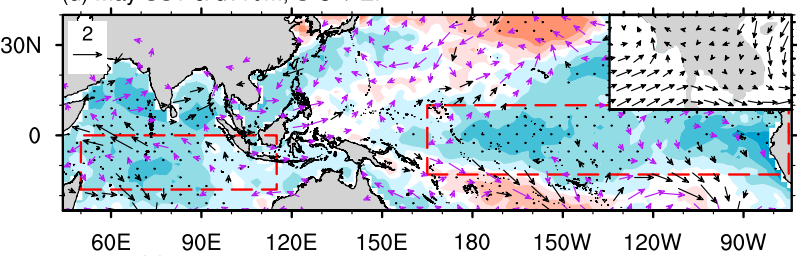

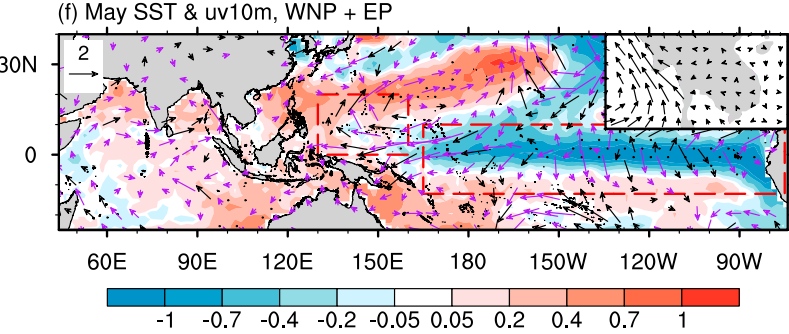

FIG. 8. Composite anomalies of (left) precipitation ( $\mathrm{mm} \mathrm{day}^{-1}$; shading) and $200-\mathrm{hPa}$ wind ( $\mathrm{m} \mathrm{s}^{-1}$; vectors, scale at the top-left corner) and (right) SST $\left({ }^{\circ} \mathrm{C}\right.$; shading) and 10-m winds $\left(\mathrm{m} \mathrm{s}^{-1}\right.$; vector, scale at the top-left corner) for the (a),(b) SIO $+\mathrm{WNP}+\mathrm{EP},(\mathrm{c}),(\mathrm{d}) \mathrm{SIO}+\mathrm{EP}$, and (e),(f) WNP+EP cases in May. Dotted areas denote that the composite precipitation and SST anomalies are significant at the $90 \%$ confidence level. Wind vectors in black denote that wind anomalies are significant at the $90 \%$ confidence level. Wind vectors in purple denote that the magnitude of wind anomalies is larger than $2 \mathrm{~m} \mathrm{~s}^{-1}$ (for 200-hPa winds) and $0.5 \mathrm{~m} \mathrm{~s}^{-1}$ (for 10-m winds) but not reaching the $90 \%$ confidence level. The insets on the top-right corner of the right panels show 10-m winds around ICP. 

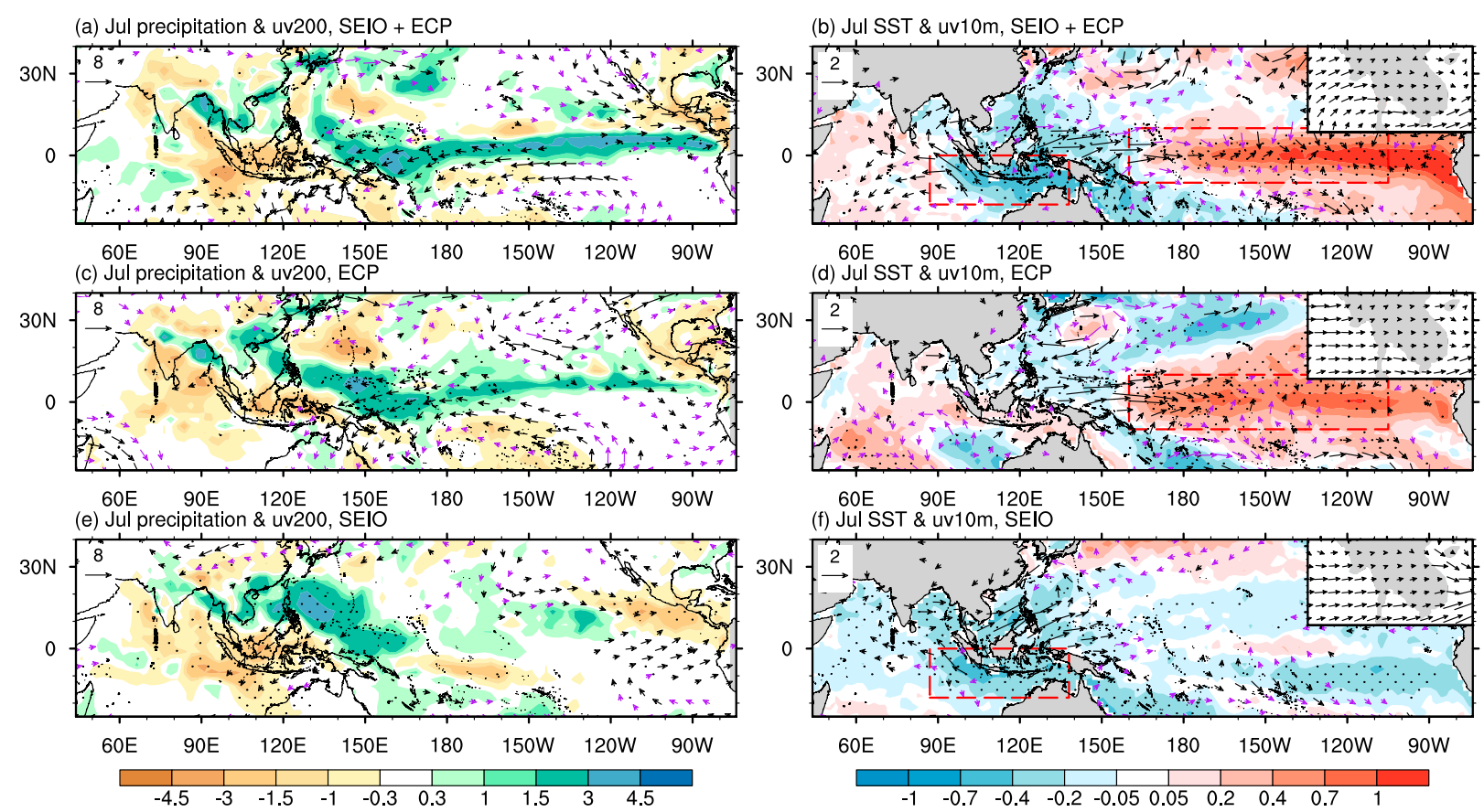

FIG. 9. As in Fig. 8, but for the (a),(b) SEIO+ECP, (c),(d) ECP, and (e),(f) SEIO cases in July.

positive WNP SST anomalies (Fig. 8f). This may be associated with increase of the convective instability due to warmer WNP SST (Hu et al. 2014).

\section{c. Influence of regional SST anomalies on rainfall variation in July}

Two SST regions are considered to analyze the individual and combined impacts of SST anomalies on precipitation in July. We distinguish three types of cases: 1) The SEIO+ECP in which positive rainfall anomalies are associated with positive ECP SST anomalies and negative SEIO SST anomalies and negative rainfall anomalies are associated with negative ECP SST anomalies and positive SEIO SST anomalies, 2) the ECP cases in which positive rainfall anomalies accompany positive ECP SST anomalies and negative rainfall anomalies accompany negative ECP SST anomalies, with weak SEIO SST anomalies, and 3) the SEIO cases in which positive rainfall anomalies accompany negative SEIO SST anomalies and negative rainfall anomalies accompany positive SEIO SST anomalies, with weak ECP SST anomalies. The specific years are listed in Table 3. Similar to the composite in May, we reverse anomalies in negative rainfall years and combine them with those in positive rainfall years when constructing the composite.

In the combined-influence cases, rainfall increases are seen along the west coast of the ICP, eastern ICP, southern China, the WNP, and the equatorial westerncentral Pacific (Fig. 9a). Anomalous low-level westerlies extend from the ECP to the SCS as a Rossby wave-type response to anomalous ECP warming (Fig. 9b). Anomalous lower-level westerlies over the north Indian Ocean and the ICP are associated with cross-equatorial flows from the SEIO caused by the SEIO cooling (Fig. 9b). Over the Maritime Continent, there are anomalous northerly winds at upper levels and anomalous southerly winds at lower levels (Figs. 9a,b). This indicates an anomalous cross-equatorial overturning circulation, which is linked to the SEIO cooling (He and $\mathrm{Wu} 2014)$. The rainfall increase around the ICP may be attributed to the above meridional vertical circulation induced by the SEIO cooling and the Rossby wave response to the ECP warming.

In the ECP cases, positive rainfall anomalies are present over the west coast of the ICP, southern China, and the equatorial western-central Pacific (Fig. 9c). Rainfall is reduced over southern Bay of Bengal and Indonesia. Anomalous lower-level westerlies and upper-level easterlies over the equatorial western Pacific are induced by positive ECP SST anomalies (Figs. 9c,d). The ICP is dominated by anomalous lower-level westerlies (Fig. 9d), but with smaller magnitude compared to the SEIO+ECP cases (Fig. 9b). This difference indicates the role of the SEIO SST anomalies. Positive SST anomalies are observed over a large part of the tropical Indian Ocean (Fig. 9d), which may be partly due to the increase in downward shortwave radiation accompanying negative rainfall anomalies there. 
(a) Oct precipitation \& uv200, WIO + EP

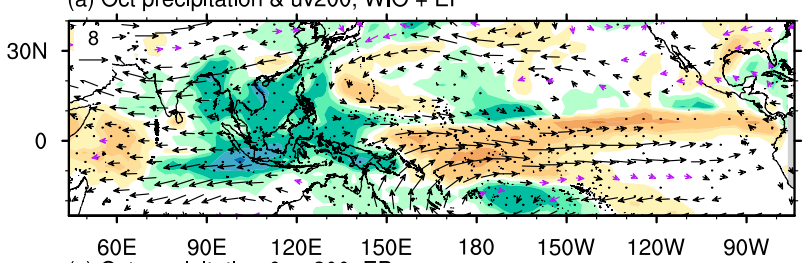

(c) Oct precipitation \& uv200, EP

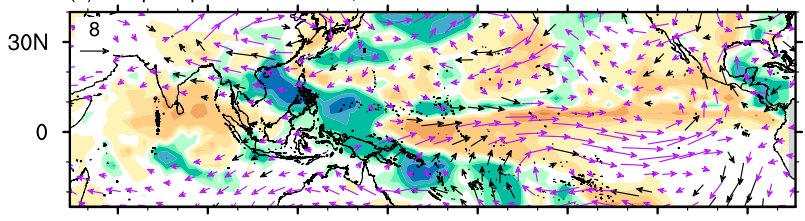

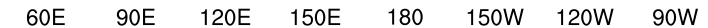
(e) Oct precipitation \& Uv200, WIO

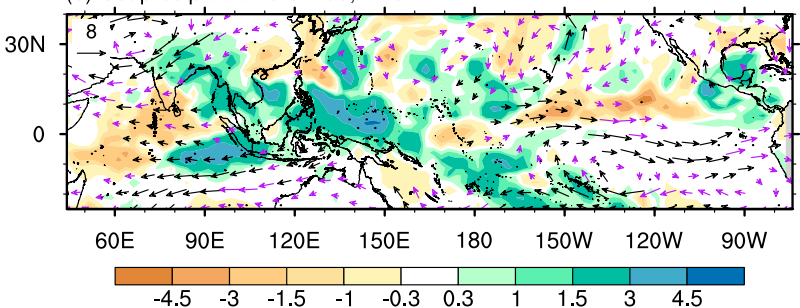

FIG. 10. As in Fig. 8, but for the (a),(b) WIO+EP, (c),(d) EP, and (e),(f) WIO cases in October. (b) Oct SST \& uv10m, WIO + EP

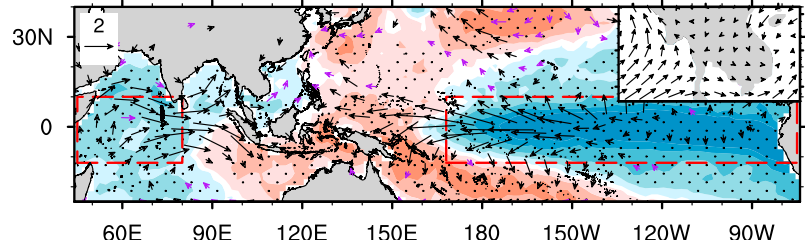

(d) Oct SST \& uv10m, EP
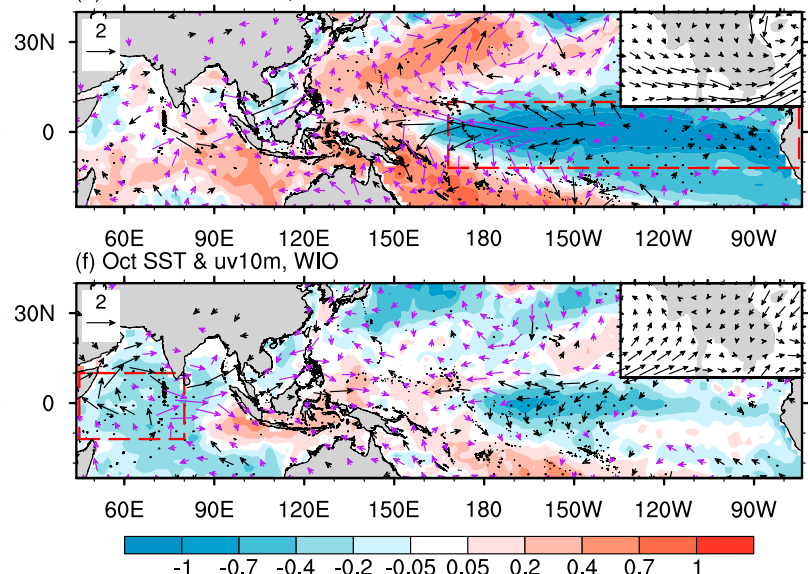

In the SEIO cases, positive rainfall anomalies cover the west coast of the ICP and eastern ICP, and the Philippine Sea and negative rainfall anomalies extend from the SEIO to the north Indian Ocean (Fig. 9e). The magnitude of rainfall anomalies over the west coast of the ICP is smaller than in the SEIO+ECP cases (Fig. 9a), which indicates a contribution of the ECP SST anomalies. Anomalous lower-level southerly winds and upper-level northerly winds are observed over the Maritime Continent (Figs. 9e,f), which are associated with negative SEIO SST anomalies (Fig. 9f). Lowerlevel cross-equatorial winds over the eastern Indian Ocean turn to westerlies and influence the SCS (Fig. 9f). That explains the rainfall increase in the eastern ICP (Fig. 9e). Anomalous winds are weak over the ECP due to lack of SST anomalies there.

\section{d. Influence of regional SST anomalies on rainfall variation in October}

The two SST regions considered for rainfall in October are EP and WIO. We distinguish the following types of cases: 1) The WIO+EP case in which positive or negative rainfall anomalies are respectively associated with negative or positive EP and WIO SST anomalies, 2 ) the EP case in which positive rainfall anomalies correspond to negative EP SST anomalies, and 3) the WIO case in which positive or negative rainfall anomalies respectively correspond to negative or positive WIO SST anomalies. The specific years are listed in Table 3.
The composite anomalies are constructed in the same manner as in May and July.

In the combined-SST anomaly cases, positive rainfall anomalies cover a large region including the ICP, SCS, SEIO, and equatorial western Pacific (Fig. 10a). Negative rainfall anomalies are observed over the WIO and EP. Anomalous lower-level easterlies and upper-level westerlies are seen over the ECP, featuring a response to the EP SST cooling (Figs. 10a,b). Opposite wind anomalies are seen over the tropical Indian Ocean in response to the WIO cooling. Correspondingly, there is anomalous lower-level convergence and upper-level divergence around the Maritime Continent and the west coast of the ICP. This demonstrates the influence of negative SST anomalies in the WIO and EP on the ICP rainfall via anomalous Walker circulation. Anomalous lower-level northeasterly winds over the northern SCS (Fig. 10b) lead to anomalous convergence and increase rainfall along the east coast of the ICP (Fig. 10a).

When the WIO SST anomalies are weak, both the wind and rainfall anomalies become weaker over the tropical Indian Ocean (Figs. 10c,d). This confirms the role of the WIO cooling. The wind and rainfall anomalies over the tropical Pacific Ocean remain similar. Anomalous lowerlevel easterlies and upper-level westerlies are observed over the ECP as a response to the EP cooling. An anomalous lower-level cyclone over the northern SCS (Fig. 10d) leads to a rainfall increase in the east coast of the ICP and the SCS (Fig. 10c). 

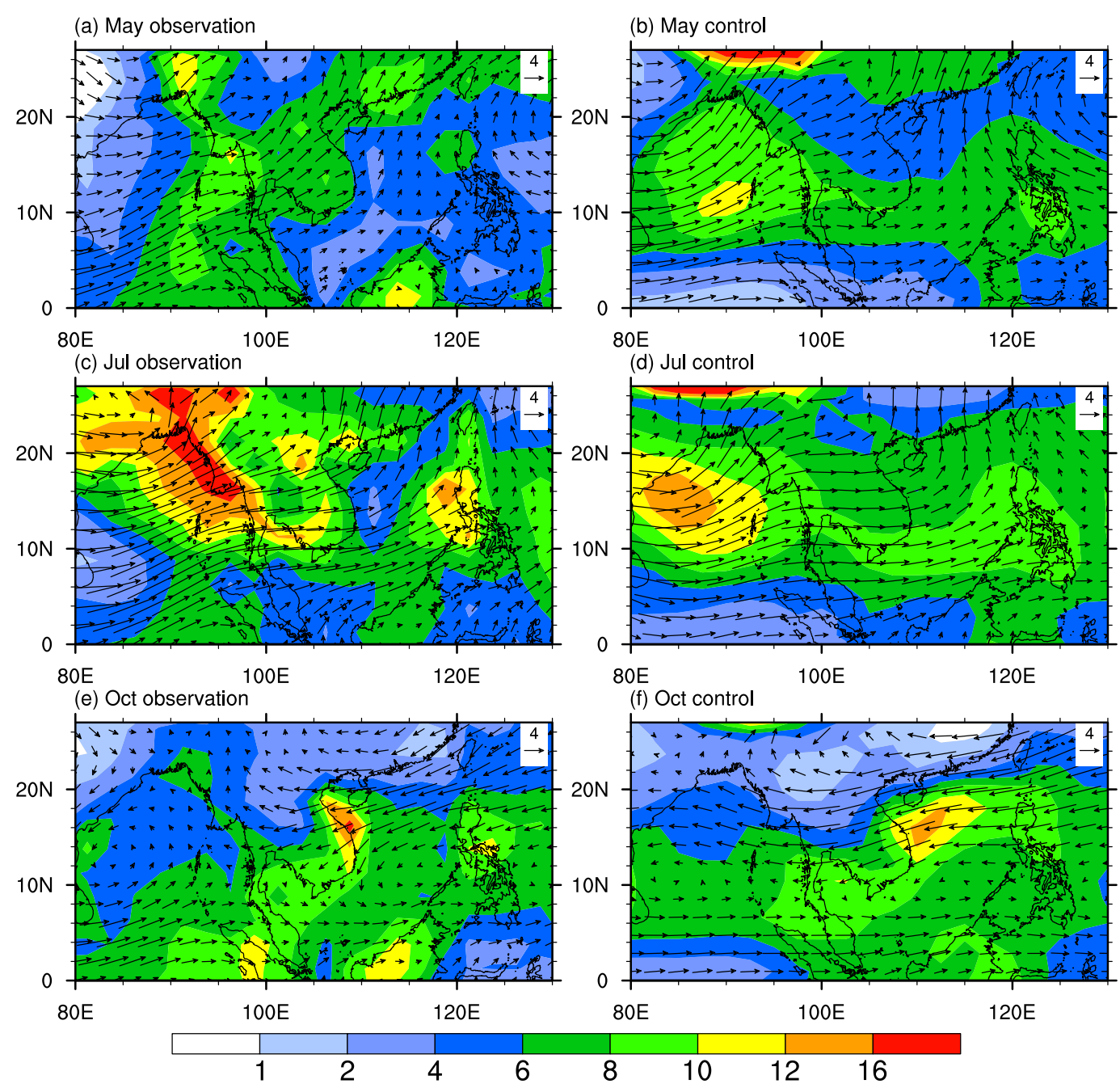

FIG. 11. Climatological mean precipitation $\left(\mathrm{mm} \mathrm{day}^{-1}\right.$; shading) and $850-\mathrm{hPa}$ winds $\left(\mathrm{m} \mathrm{s}^{-1}\right.$; vectors, scale at the topright corner) in (left) the observations and (right) the control run in (a),(b) May, (c),(d) July, and (e),(f) October.

Without the EP SST effect, the wind anomalies become weaker not only over the tropical Pacific Ocean, but also over the tropical Indian Ocean (Figs. 10e,f). Positive rainfall anomalies become smaller over the ICP and the SCS (Fig. 10e). An anomalous lower-level cyclone appears to be the main circulation system for rainfall increase over the west coast of the ICP. The above features appear to suggest a larger impact of the EP SST anomalies than the WIO SST anomalies on the ICP rainfall in October.

\section{Results of numerical experiments}

In this section, we conduct numerical experiments with the CAM5.2 to confirm the influences of tropical IndoPacific SST anomalies in different regions on the ICP rainfall. The control run of 30-yr integration is conducted with monthly climatological SST imposed in global oceans. Figure 11 provides a comparison of mean precipitation and 850-hPa wind in May, July, and October based on the $30-y r$ control run and the observations. The simulated precipitation over the ICP is smaller than the observations and there are differences in the location of rainfall centers between the model simulations and observations. The distribution and seasonal change of mean precipitation and atmospheric circulation in the rainy season appears similar to the observations.

Ten sensitivity experiments are conducted with SST anomalies added in different regions. The SST anomalies imposed in the sensitivity experiments are based on the composite SST anomalies in May, July, and October, respectively, as shown in the boxes of Figs. 7b, 7d, and 7f. Table 4 lists the sensitivity experiments with information of source and domain of imposed SST anomalies. In the 
TABLE 4. List of numerical experiments with information of source and domain of specified SST anomalies. Refer to the text for domains of imposed SST anomalies.

\begin{tabular}{cccc}
\hline \hline Group & Name & Source of SST anomaly & Domain of SST anomaly \\
\hline Group 1 (May) & SIO+WNP+EP & Composite in May (Fig. 7b): negative SST & SIO, WNP, EP \\
& EP & anomalies in EP and SIO and positive & EP \\
& SIO & SST anomalies in WNP & SIO \\
WNP & & WNP \\
Group 2 (Jul) & SEIO+ECP & Composite in July (Fig. 7d): positive SST & SEIO, ECP \\
& ECP & anomalies in ECP and negative SST & ECP \\
Group 3 (Oct) & SIO & anomalies in SEIO & SEIO \\
& EP & Composite in October (Fig. 7f): Negative & WIO, EP \\
& WIO & SST anomalies in EP and WIO & EP \\
& & & WIO \\
\hline
\end{tabular}

first group (corresponding to May precipitation), four experiments are conducted with the SST anomalies added only in the EP $\left(13^{\circ} \mathrm{S}-10^{\circ} \mathrm{N}, 165^{\circ} \mathrm{E}-75^{\circ} \mathrm{W}\right)$, SIO $\left(18^{\circ} \mathrm{S}-0^{\circ} \mathrm{N}, 50^{\circ}-115^{\circ} \mathrm{E}\right)$, and WNP $\left(0^{\circ} \mathrm{S}-20^{\circ} \mathrm{N}, 130^{\circ}-\right.$ $160^{\circ} \mathrm{E}$ ), respectively, and in all these three regions simultaneously (boxes in Fig. 7b). In the second group (corresponding to July precipitation), three experiments are conducted with SST anomalies added only in the ECP $\left(10^{\circ} \mathrm{S}-10^{\circ} \mathrm{N}, 160^{\circ} \mathrm{E}-105^{\circ} \mathrm{W}\right)$ and SEIO $\left(18^{\circ} \mathrm{S}-0^{\circ} \mathrm{N}\right.$, $\left.87^{\circ}-138^{\circ} \mathrm{E}\right)$, respectively, and in both regions simultaneously (boxes in Fig. 7d). In the third group (corresponding to October precipitation), three experiments are conducted with the SST anomalies added in the EP $\left(12^{\circ} \mathrm{S}-10^{\circ} \mathrm{N}, 168^{\circ} \mathrm{E}-75^{\circ} \mathrm{W}\right)$ and $\mathrm{WIO}\left(12^{\circ} \mathrm{S}-10^{\circ} \mathrm{N}, 45^{\circ}-\right.$ $\left.80^{\circ} \mathrm{E}\right)$, respectively, and in both regions simultaneously (boxes in Fig. 7f). These 10 sensitivity experiments are integrated for 10 years, forced by nonvarying SST anomalies added to annual varying climatological SST in the specific regions and climatological SST elsewhere. The initial state of these sensitivity experiments is the same, which is the first date of the second year integration of the control run. The 10-yr mean differences between the sensitivity experiment and the control run are used to represent the response of the model to the specific SST anomalies. In the following, we show the differences of May-June, July-August, and OctoberNovember between the sensitivity experiments and the control run as the model response is similar in May and June, in July and August, and in October and November.

In the combined-SST forced simulations of MayJune, the rainfall and lower-level wind response in the model (Fig. 12a) displays a distribution similar to the observations (Figs. 8a,b). This confirms the combined impacts of the SST anomalies. Two discrepancies are noted between the model simulations and the observations. One is that the westerly wind and positive rainfall response is too large over the north Indian Ocean in the model. The other is that the easterly wind and negative rainfall response over the subtropical East Asia-WNP region in the model is not seen in the observations. In the EP SST forced simulations, the wind and rainfall response is very similar to that in the combined SST forced simulations over the tropical Pacific Ocean, whereas the response is weak over the tropical Indian Ocean (Fig. 12b). The rainfall response is weak along the west ICP. In the SIO SST-forced simulations, the wind and rainfall response is similar to the combined SST-forced simulations in the tropical Indian Ocean, whereas the response is weak over the tropical Pacific Ocean (Fig. 12c). In response to the WNP SST forcing, the model produces a lower-level cyclone and rainfall increase around the Philippines (Fig. 12d), which is similar to the combined SST forced simulation. However, the cyclone and rainfall increase does not extend to the ICP. The model results suggest that all the three regional SST anomalies influence the ICP rainfall in May-June with larger impacts of EP and SIO SST anomalies. When the SST anomalies exist concurrently in the three regions, their cooperation is likely to induce more obvious rainfall anomalies over the ICP.

In the combined SST forced simulations of JulyAugust, the lower-level wind and rainfall response in the model (Fig. 13a) displays a spatial distribution similar to the observations (Figs. 9a,b), but it extends too much westward to the SCS and the tropical Indian Ocean compared to the observations. In the ECP SST-forced simulations, the wind and rainfall response is close to that in the combined SST-forced simulations (Figs. 13a,b). The magnitude of wind and rainfall response appears too large compared to the observational composite of the ECP case (Figs. 9c,d). The excessive response is a drawback of the specified SST simulations (Wu and Kirtman 2004, 2005). In the SEIO SST-forced simulations, the model produces westerlies and rainfall increase over the north Indian Ocean, the ICP, the SCS, and the Philippine Sea (Fig. 13c), resembling the observational composite of the SEIO case (Figs. 9e,f). The magnitude of response is 
(a) $\mathrm{SIO}+\mathrm{WNP}+\mathrm{EP}$

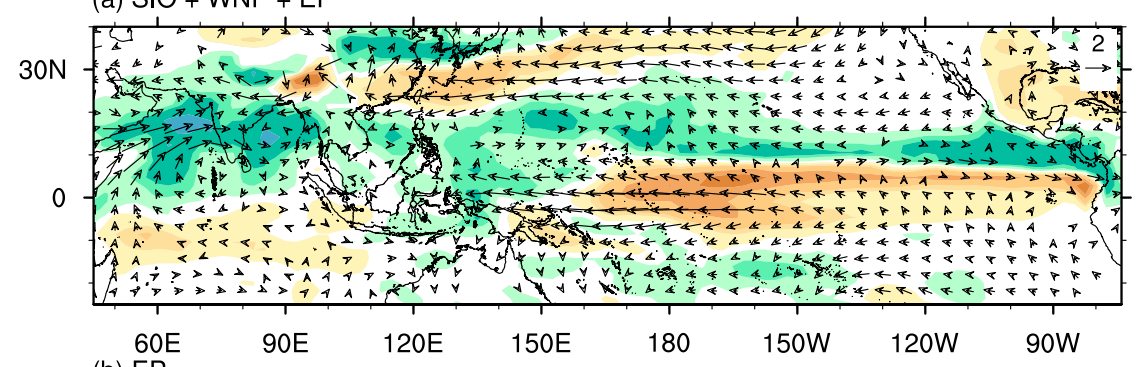

(b) 60

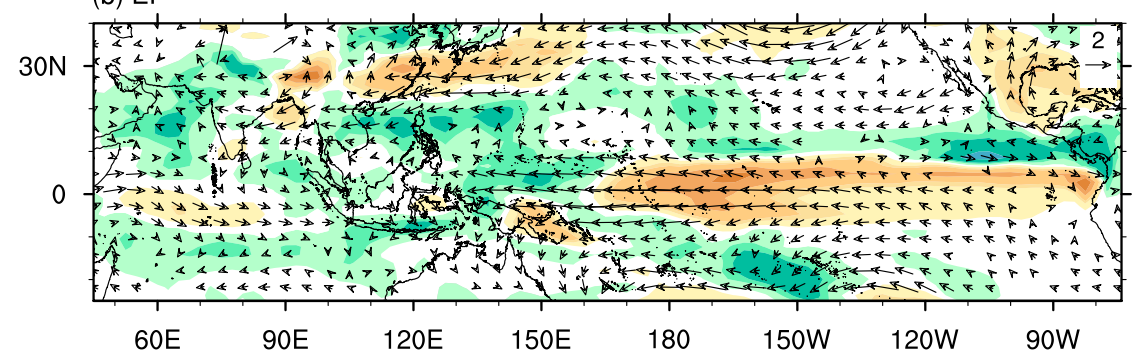

(c) $\mathrm{SIO}$
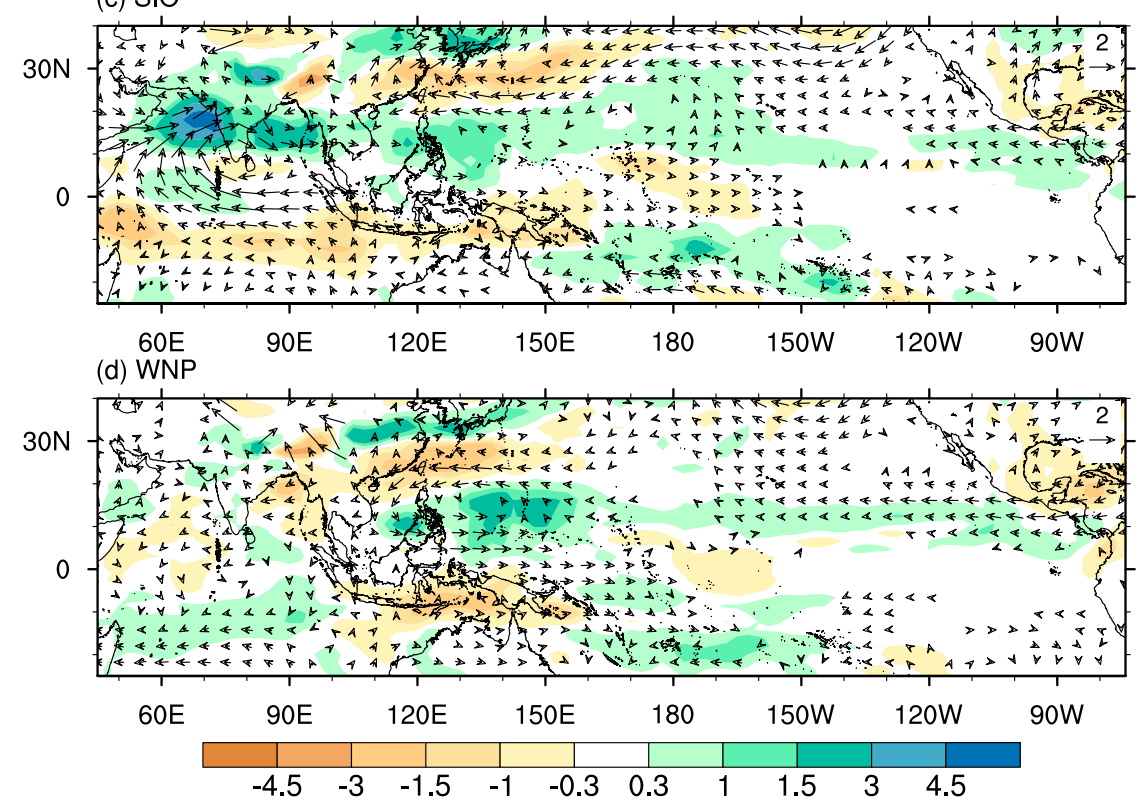

FIG. 12. The response of May-June rainfall (mm day ${ }^{-1}$; shading) and $850-\mathrm{hPa}$ winds $\left(\mathrm{m} \mathrm{s}^{-1}\right.$; vectors, scale at the top-right corner) to SST anomalies in the (a) SIO+WNP+EP, (b) EP, (c) SIO, and (d) WNP cases. Only wind vectors with magnitude larger than $0.2 \mathrm{~m} \mathrm{~s}^{-1}$ are plotted.

much smaller than that in the ECP SST-forced simulations (Figs. 13b,c). The model results suggest that both the ECP warming and the SEIO cooling contribute to the ICP rainfall variability in July-August. However, the contribution of the ECP warming is much larger than the SEIO cooling and the combined influences are mainly determined by the ECP SST effect.

In the combined SST-forced simulations of OctoberNovember, the lower-level wind and rainfall response in the model (Fig. 14a) is similar to the observations
(Figs. 10a,b). In comparison, the magnitude of rainfall is smaller in the model than in the observations. In the EP SST-forced simulations, the pattern of wind and rainfall response resembles closely the combined SSTforced simulations except for rainfall over the WIO (Figs. 14a,b). It is also similar to the observational composite of the EP SST case (Figs. 10c,d). In the WIO SST forced simulations, the model produces lower-level westerlies over the north Indian Ocean and rainfall increase around the ICP (Fig. 14c). The magnitude of the 

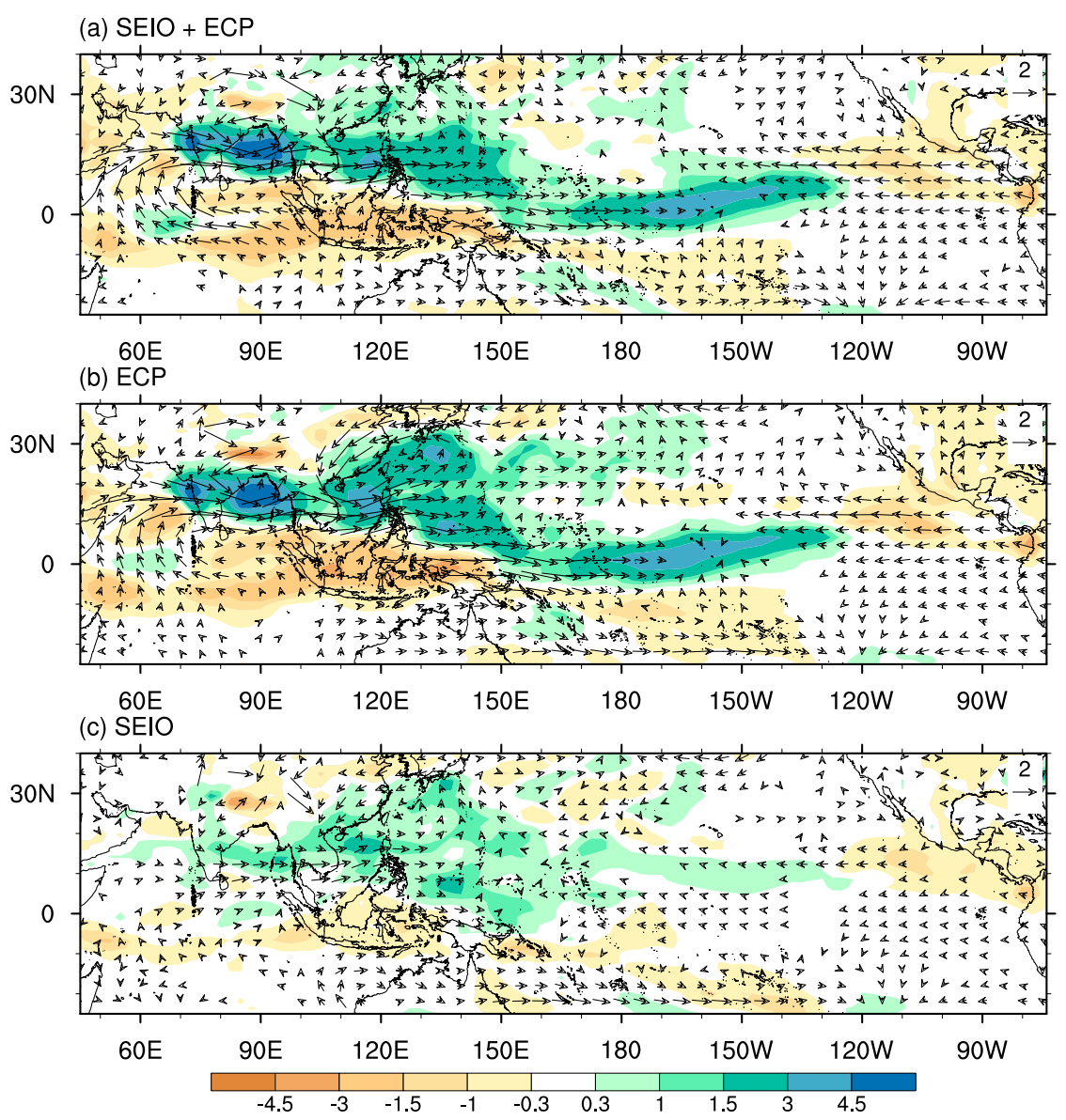

FIG. 13. The response of July-August rainfall ( $\mathrm{mm} \mathrm{day}^{-1}$; shading) and $850-\mathrm{hPa}$ winds $\left(\mathrm{m} \mathrm{s}^{-1}\right.$; vectors, scale at the top-right corner) to SST anomalies in the (a) SEIO+ECP, (b) ECP, and (c) SEIO cases. Only wind vectors with magnitude larger than $0.2 \mathrm{~m} \mathrm{~s}^{-1}$ are plotted.

rainfall over the ICP is smaller when compared with the EP SST-forced simulations (Figs. 14b,c). The wind and rainfall response is small over the tropical Pacific Ocean (Fig. 14c). The model results suggest that the EP SST forcing plays a more important role than the WIO SST in the ICP rainfall variability in October-November, which is consistent with the observations.

\section{Summary and discussion}

This study provides a systematic analysis of the influences of the tropical Indo-Pacific SST anomalies on the interannual variations of precipitation over the ICP during the rainy season. We not only distinguish the rainfall variation in different stages of the rainy season, but also investigate the individual and combined impacts of the SST anomalies in different regions. Thus, this study provides a more comprehensive view than previous studies of interannual variations of precipitation over the ICP in the rainy season and the influences of the Indo-Pacific SST anomalies.

The relation of the ICP rainfall to ENSO varies with the stage of the rainy season. More rainfall in May-June tends to occur along the west coast in the La Niña decaying years. More rainfall in July-August tends to appear along the west coast and over the eastern mountainous region in the La Niña decaying years and/or El Niño developing years. More rainfall in October-November tends to occur along the east coast in the La Niña developing years. Rainfall variation in September along the east coast has a weaker relationship to ENSO. The interannual variation of rainfall in May-June along the west coast is associated with SST anomalies in the EP, SIO, and WNP. The interannual variation of rainfall in July-August along the west coast and over the eastern mountains is related to SST anomalies in the ECP and SEIO. The interannual variation of rainfall in October-November along the east coast is affected by SST anomalies in the EP and WIO. 

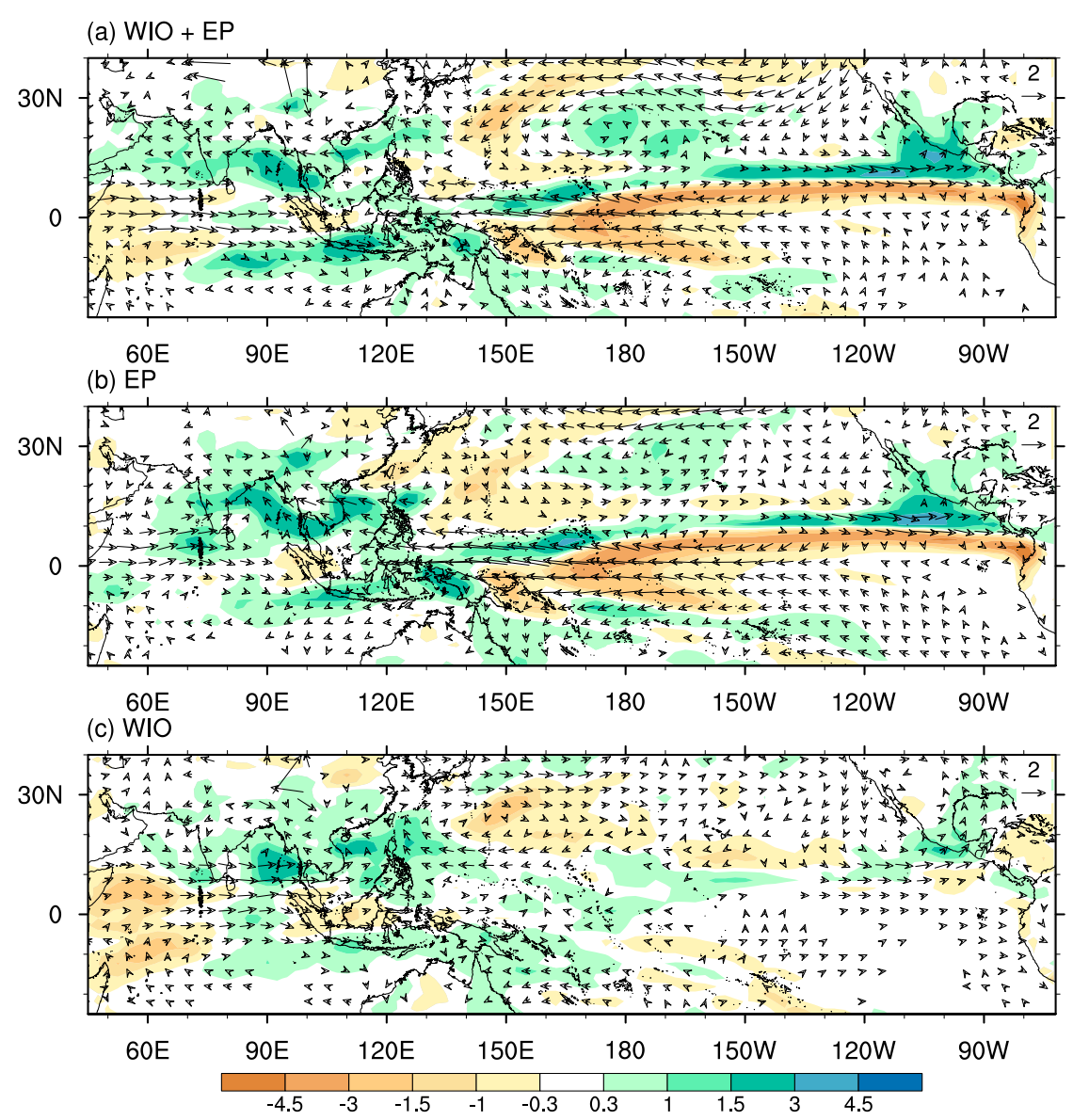

FIG. 14. The response of October-November rainfall (mm day ${ }^{-1}$; shading) and $850-\mathrm{hPa}$ winds $\left(\mathrm{m} \mathrm{s}^{-1}\right.$; vectors, scale at the top-right corner) to SST anomalies in the (a) WIO+EP, (b) EP, and (c) WIO cases. Only wind vectors with the magnitude larger than $0.2 \mathrm{~m} \mathrm{~s}^{-1}$ are plotted.

The composite analysis based on different combinations of regional SST anomalies indicates the importance of cooperation of the Indo-Pacific SST forcing.

Processes for influence of concurrent SST anomalies in different regions on the ICP rainfall variability are similar to those in previous studies (Chen and Yoon 2000; Wu et al. 2012; He and Wu 2014; $\mathrm{Hu}$ et al. 2014; Wu and $\mathrm{He}$ 2017). The influence of the EP SST anomalies on MayJune rainfall over the ICP is through an anomalous Walker circulation. The SIO SST anomalies influence the ICP rainfall in May-June through anomalous crossequatorial flows that continue to extend to the ICP. The influence of the WNP SST anomalies may be interpreted as a Rossby wave response and a modulation of local convective instability. The ECP SST influence on the ICP rainfall in July-August is through a westward extension of the Rossby wave response. The influence of the SEIO SST anomalies is through an anomalous cross-equatorial overturning circulation. The influence of the EP and WIO
SST anomalies on the October-November rainfall over the ICP is through anomalous Walker circulation.

The results of numerical experiments with SST anomalies specified in different region confirm the roles of the Indo-Pacific SST anomalies on the rainfall variation over the ICP in different stages of the rainy season. The model experiments also illustrate that the coherent impacts of SST anomalies in different regions are more significant than impacts of SST anomalies in individual regions. In addition, the model results support the relative influences of regional SST anomalies on the May-June, July-August, and October-November rainfall variations derived from the observational analysis. The model, however, overestimates the impacts of the ECP warming on the July-August rainfall.

As shown in Table 3, there are limited numbers of years in some cases. The robustness of the features based on the observations needs to be validated using more data by extending the analysis period. Another feature is that 
some cases have more numbers of years in one sign of rainfall anomalies, such as the $\mathrm{SIO}+\mathrm{WNP}+\mathrm{EP}$ case in May and the EP case in October. The asymmetric influences of the SST anomalies are worthy of investigation. Another issue is whether the relative roles of the SST anomalies in different regions in the ICP rainfall variability may vary with the time period and with the change in the characteristics of ENSO.

This study focuses on interannual variations of rainfall over the ICP and the influences of regional SST anomalies. Intraseasonal and interdecadal variations of rainfall over the ICP and their relationships to SST in different regions need to be studied in the future. In addition, the plausible contributions of the land surface status and the associated processes are issues of concern in future studies.

Acknowledgments. Comments of three anonymous reviewers are appreciated. This study is supported by grants from the National Natural Science Foundation of China (41775080, 41661144016, 41661144017, 41530425, and 41721004). The GPCC and GPCP data were obtained from https://www.esrl.noaa.gov/psd/. The ERAInterim data were obtained from https://www.ecmwf.int/. The HadISST SST data were obtained from https://www. metoffice.gov.uk/hadobs/hadisst/.

\section{REFERENCES}

Adler, R. F., and Coauthors, 2003: The version-2 Global Precipitation Climatology Project (GPCP) monthly precipitation analysis (1979-present). J. Hydrometeor., 4, 1147-1167, https://doi.org/ 10.1175/1525-7541(2003)004<1147:TVGPCP $>2.0 . C O ; 2$.

Becker, A., P. Finger, A. Meyer-Christoffer, B. Rudolf, K. Schamm, U. Schneider, and M. Ziese, 2013: A description of the global land-surface precipitation data products of the Global Precipitation Climatology Centre with sample applications including centennial (trend) analysis from 1901present. Earth Syst. Sci. Data, 5, 71-99, https://doi.org/10.5194/ essd-5-71-2013.

Chen, T.-C., and J.-H. Yoon, 2000: Interannual variation in Indochina summer monsoon rainfall: Possible mechanism. J. Climate, 13, 1979-1986, https://doi.org/10.1175/1520-0442(2000)013<1979: IVIISM $>2.0 . \mathrm{CO} ; 2$.

_ , J.-D. Tsay, M.-C. Yen, and J. Matsumoto, 2012: Interannual variation of the late fall rainfall in central Vietnam. J. Climate, 25, 392-413, https://doi.org/10.1175/JCLI-D-11-00068.1.

Dee, D. P., and Coauthors, 2011: The ERA-Interim reanalysis: Configuration and performance of the data assimilation system. Quart. J. Roy. Meteor. Soc., 137, 553-597, https://doi.org/ 10.1002/qj.828.

Ge, F., X. Zhi, Z. A. Babar, W. Tang, and P. Chen, 2017: Interannual variability of summer monsoon precipitation over the Indochina Peninsula in association with ENSO. Theor. Appl. Climatol., 128, 523-531, https://doi.org/10.1007/s00704-015-1729-y.

$\mathrm{He}, \mathrm{Z}$., and R. Wu, 2014: Indo-Pacific remote forcing in summer rainfall variability over the South China Sea. Climate Dyn., 42, 2323-2337, https://doi.org/10.1007/s00382-014-2123-7.
Hu, W., R. Wu, and Y. Liu, 2014: Relation of the South China Sea precipitation variability to tropical Indo-Pacific SST anomalies during spring-to-summer transition. J. Climate, 27, 54515467, https://doi.org/10.1175/JCLI-D-14-00089.1.

Hurrell, J. W., and Coauthors, 2013: The Community Earth System Model: A framework for collaborative research. Bull. Amer. Meteor. Soc., 94, 1339-1360, https://doi.org/10.1175/BAMS-D12-00121.1.

Kay, J. E., and Coauthors, 2015: The Community Earth System Model (CESM) Large Ensemble Project: A community resource for studying climate change in the presence of internal climate variability. Bull. Amer. Meteor. Soc., 96, 1333-1349, https://doi.org/10.1175/BAMS-D-13-00255.1.

Kirtphaiboon, S., P. Wongwises, A. Limsakul, S. Sooktawee, and U. Humphries, 2014: Rainfall variability over Thailand related to the El Niño-Southern Oscillation (ENSO). J. Sustainable Energy Environ., 5, 37-42.

Kripalani, R. H., and A. Kulkarni, 1997: Rainfall variability over South-East Asia-Connections with Indian monsoon and ENSO extremes: New perspectives. Int. J. Climatol., 17, 11551168, https://doi.org/10.1002/(SICI)1097-0088(199709)17: $11<1155::$ AID-JOC188>3.0.CO;2-B.

_ and - 1998: The relationship between some large-scale atmospheric parameters and rainfall over Southeast Asia: A comparison with features over India. Theor. Appl. Climatol., 59, 1-11, https://doi.org/10.1007/s007040050009.

Lau, K. M., and S. Yang, 1997: Climatology and interannual variability of the Southeast Asian summer monsoon. Adv. Atmos. Sci., 14, 141-162, https://doi.org/10.1007/s00376-997-0016-y.

Limsakul, A., and P. Singhruck, 2016: Long-term trends and variability of total and extreme precipitation in Thailand. Atmos. Res., 169, 301-317, https://doi.org/10.1016/j.atmosres.2015.10.015.

_ - S. Limjirakan, and B. Suthamanuswong, 2007: Spatio-temporal changes in total annual rainfall and the annual number of rainy days in Thailand. J. Environ. Res., 29, 1-21.

,-- , and -2010 : Asian summer monsoon and its associated rainfall variability in Thailand. Environ. Asia, 3, 79-89, https://doi.org/10.14456/ea.2010.27.

Nguyen, D.-Q., R. James, and M. James, 2014: Variations of surface temperature and rainfall in Vietnam from 1971 to 2010. Int. J. Climatol., 34, 249-264, https://doi.org/10.1002/joc.3684.

Nguyen, T. D., C. Uvo, and D. Rosbjerg, 2007: Relationship between the tropical Pacific and Indian Ocean sea-surface temperature and monthly precipitation over the central highlands, Vietnam. Int. J. Climatol., 27, 1439-1454, https://doi.org/ 10.1002/joc.1486.

North, G. R., T. L. Bell, R. F. Cahalan, and F. J. Moeng, 1982: Sampling errors in the estimation of empirical orthogonal functions. Mon. Wea. Rev., 110, 699-706, https://doi.org/ 10.1175/1520-0493(1982)110<0699:SEITEO > 2.0.CO;2.

Rayner, N. A., D. E. Parker, E. B. Horton, C. K. Folland, L. V. Alexander, D. P. Rowell, E. C. Kent, and A. Kaplan, 2003: Global analyses of sea surface temperature, sea ice, and night marine air temperature since the late nineteenth century. J. Geophys. Res., 108, 4407, https://doi.org/10.1029/2002JD002670.

Singhrattna, N., B. Rajagopalan, K. Krishna Kumar, and M. Clark, 2005: Interannual and interdecadal variability of Thailand summer monsoon season. J. Climate, 18, 1697-1708, https:// doi.org/10.1175/JCLI3364.1.

Takahashi, H. G., and T. Yasunari, 2008: Decreasing trend in rainfall over Indochina during the late summer monsoon: Impact of tropical cyclones. J. Meteor. Soc. Japan, 86, 429-438, https://doi.org/10.2151/jmsj.86.429. 
H. Fujinami, T. Yasunari, J. Matsumoto, and S. Baimoung, 2015: Role of tropical cyclones along the monsoon trough in the 2011 Thai flood and interannual variability. J. Climate, 28, 1465-1476, https://doi.org/10.1175/JCLI-D-14-00147.1

Tao, S., and L. Chen, 1987: A review of recent research on the East Asian summer monsoon in China. Monsoon Meteorology, C.-P. Chang and T. N. Krishnamurti, Eds., Oxford University Press, 60-92.

Wang, B., and LinHo, 2002: Rainy season of the Asian-Pacific summer monsoon. J. Climate, 15, 386-398, https://doi.org/ 10.1175/1520-0442(2002)015<0386:RSOTAP $>2.0 . C O ; 2$.

Wen, M., J. He, and Z. Xiao, 2004: Impact of the convection over the Indo-China Peninsula on the onset of SCS summer monsoon. Chin. J. Atmos. Sci., 28, 864-875.

$\mathrm{Wu}, \mathrm{R}$., and B. P. Kirtman, 2004: Impacts of Indian Ocean on the Indian monsoon-ENSO relationship. J. Climate, 17, 30373054, https://doi.org/10.1175/1520-0442(2004)017<3037: IOTIOO $>2.0 . \mathrm{CO} ; 2$.

- and — 2005: Role of Indian and Pacific Ocean air-sea coupling in tropical atmospheric variability. Climate Dyn., 25, 155-170, https://doi.org/10.1007/s00382-005-0003-x.

$\longrightarrow$, and - 2007: Regimes of seasonal air-sea interaction and implications for performance of forced simulations. Climate Dyn., 29, 393-410, https://doi.org/10.1007/s00382-007-0246-9.

— spring to summer transition over the South China Sea. J. Climate, 30, 9665-9678, https://doi.org/10.1175/JCLI-D-170215.1.

, B. P. Kirtman, and K. Pegion, 2006: Local air-sea relationship in observations and model simulations. J. Climate, 19, 4914-4932, https://doi.org/10.1175/JCLI3904.1.

- - - and V. Krishnamurthy, 2008: An asymmetric mode of tropical Indian Ocean rainfall variability in boreal spring. J. Geophys. Res., 113, D05104, https://doi.org/10.1029/ 2007JD009316.

, S. Yang, Z.-P. Wen, G. Huang, and K. Hu, 2012: Interdecadal change in the relationship of southern China summer rainfall with tropical Indo-Pacific SST. Theor. Appl. Climatol., 108, 119-133, https://doi.org/10.1007/s00704-011-0519-4.

— G. Huang, Z. Du, and K. Hu, 2014: Cross-season relation of the South China Sea precipitation variability between winter and summer. Climate Dyn., 43, 193-207, https://doi.org/ 10.1007/s00382-013-1820-y.

Xu, H., J. He, M. Wen, and M. Dong, 2002: A numerical study of effects of the Indo-China Peninsula on the establishment and maintenance of the South China Sea summer monsoon. Chin. J. Atmos. Sci., 26 (3), 330-342.

_ S.-P. Xie, Y.-Q. Wang, W. Zhuang, and D.-X. Wang, 2007: 2007: Orographic effects on South China Sea summer climate. Assimilation of Remote Sensing and In Situ Data in Modern Numerical Weather and Environmental Prediction Models, X. Zou, D. Barker, and F.-Xavier Le Dimet, Eds., International Society for Optical Engineering (SPIE Proceedings, Vol. 6685), 66850K, https://doi.org/10.1117/12.730375.

Yang, Y., and R. Wu, 2019: Seasonal variation of precipitation over the Indochina Peninsula and its impact on the South China Sea spring warming. Int. J. Climatol., 39, 1618-1633, https:// doi.org/10.1002/joc.5904.

Yen, M.-C., T.-C. Chen, H.-L. Hu, R.-Y. Tzeng, D. T. Dinh, T. Nguyen Tan, and C. J. Wong, 2011: Interannual variation of the fall rainfall in central Vietnam. J. Meteor. Soc. Japan, 89A, 259-270, https://doi.org/10.2151/jmsj.2011-A16.

Zhang, Y., and Y. Qian, 2002: Mechanism of thermal features over the Indo-China peninsula and possible effects on the onset of the South China Sea monsoon. Adv. Atmos. Sci., 19, 885-900, https://doi.org/10.1007/s00376-002-0053-5.

_ T. Li, B. Wang, and G. X. Wu, 2002: Onset of the summer monsoon over the Indochina Peninsula: Climatology and interannual variations. J. Climate, 15, 3206-3221, https://doi.org/ 10.1175/1520-0442(2002)015<3206:OOTSMO > 2.0.CO;2.

Zveryaev, I. I., and M. P. Aleksandrova, 2004: Differences in rainfall variability in the South and Southeast Asian summer monsoons. Int. J. Climatol., 24, 1091-1107, https://doi.org/ 10.1002/joc. 1044 . 